\title{
1 Review
}

2 Monitoring the Redox Status in Multiple Sclerosis

\author{
Masaru Tanaka ${ }^{1,2}$ and László Vécsei ${ }^{1,2, *}$ \\ 1 MTA-SZTE, Neuroscience Research Group, Semmelweis u. 6, Szeged, H-6725 Hungary; \\ tanaka.masaru.1@med.u-szeged.hu \\ 2 Department of Neurology, Interdisciplinary Excellence Centre, Faculty of Medicine, University of Szeged, \\ Semmelweis u. 6, H-6725 Szeged, Hungary \\ * Correspondence: vecsei.laszlo@med.u-szeged.hu; Tel.: +36-62-545-351
}

Abstract: Worldwide, over 2.2 million people are suffered from multiple sclerosis (MS), a multifactorial demyelinating disease of the central nervous system. MS is characterized by a wide range of motor, autonomic, and psychobehavioral symptoms including depression, anxiety, and dementia. The blood, cerebrospinal fluid, and postmortem brain samples of MS patients evidenced the disturbance of reduction-oxidation (redox) homeostasis such as the alterations of oxidative and antioxidative enzyme activities and the presence of degradation products. This review article discussed the components of redox homeostasis including reactive chemical species, oxidative enzymes, antioxidative enzymes, and degradation products. The reactive chemical species covered frequently discussed reactive oxygen/nitrogen species, infrequently featured reactive chemicals such as sulfur, carbonyl, halogen, selenium, and nucleophilic species that potentially act as reductive as well as pro-oxidative stressors. The antioxidative enzyme systems covered the nuclear factor erythroid-2-related factor 2 (NRF2)-Kelch-like ECH-associated protein 1 (KEAP1) signaling pathway. The NRF2 and other transcriptional factors potentially become a biomarker sensitive to the initial phase of oxidative stress. Altered components of the redox homeostasis in MS were discussed in search of a diagnostic, prognostic, predictive, and/or therapeutic biomarker. Finally, monitoring a battery of reactive chemical species, oxidative enzymes, antioxidative enzymes and degradation products helps evaluate the redox status of MS patients to expedite building personalized treatment plans for the sake of better quality of life.

Keywords: oxidative stress; redox; antioxidant; multiple sclerosis; biomarker; neurodegenerative disease; personalized medicine

\section{Introduction}

Multiple sclerosis (MS) is an immune-mediated demyelinating disease of the brain and spinal cord, which suffers over 2.2 million people worldwide and affects primarily young adults from 20 to 40 years of age. After one to two decades many MS patients enter a progressive phase of the disease. As survival has been improved, MS patients are suffered throughout adult life. Years lived with disability begin to increase steeply early in the second decade of life and disability-adjusted life years peak in the sixth decade of life [1]. MS encompasses a wide range of symptoms from motor and autonomic dysfunctions to psychobehavioral disturbances including gait difficulties, paresthesia, spasticity, vision problems, dizziness and vertigo, incontinence, constipation, sexual disturbances, pain, cognitive and emotional changes, anxiety, and depression [2-5]. Increase risk of depression and painful conditions in chronic illness are likely mediated by the kynurenine pathway of tryptophan metabolism [6,7].

Several genetic susceptibility, environmental factors, and ageing process have been proposed to alter the risk of developing MS, but the underlying cause of the disease remains unknown [8,9]. The most typical pathomechanism involved in MS is simultaneous inflammatory and neurodegenerative processes [10,11]. Main pathological findings of MS include the blood-brain barrier disruption, 
multifocal inflammation, demyelination, oligodendrocyte loss, reactive gliosis, and axonal degeneration [12]. Multifocal immune-mediated destruction of myelin and oligodendrocytes leading to progressive axonal loss is a main cause of neurological deficits in MS [13-15].

The diagnosis of MS is confirmed by the presence of two or more multifocal inflammatory or demyelinating attacks in central nervous system (CNS) with objective clinical evidence, a single attack with magnetic resonance imaging (MRI)-detected lesions and positive cerebrospinal fluid (CSF) analysis, or insidious neurological progression with positive brain MRI or CSF analysis [16]. The symptomatic course classifies MS into four subtypes. Approximately $85 \%$ of MS patients have alternating episodes of neurological disability and recovery which last for many years, termed relapsing-remitting MS (RRMS). Almost 90\% of RRMS patients progress to steady neurological decline within 25 years, termed secondary progressive MS (SPMS). Nearly $10 \%$ of MS patients are suffered from steady deterioration of neurological functions without recovery, termed primary progressive MS (PPMS). As few as 5\% of MS patients present progressive neurological deficits with acute attacks with or without recovery, termed progressive-relapsing MS (PRMS) [17]. However, PRMS is no longer considered a subtype of MS and now grouped into PPMS with active disease of new symptoms or changes in MRI scan [18]. In addition, clinically isolated syndrome (CIS) is a single episode of monofocal or multifocal neurological deficits that lasts at least 24 hours. CIS is one of the MS disease courses [12].

As in other neurodegenerative diseases, MS is a clinically classified disease of CNS in which multifactorial factors including genetic, environmental, socioeconomic, cultural, personal lifestyle, and ageing play an initial role to form a causative complex, eventually converging into similar pathognomonic clinical pictures [4]. Inflammatory and demyelinating attacks are unique manifestations in MS, but different pathomechanisms govern the distinguished clinical courses in each subtype of MS.

Currently there is no cure for MS. Disease modifying therapy is the mainstay of MS treatment. Immunomodulators, immunosuppressors, and cytotoxic agents are main groups of medicine. Immunomodulators such as interferon beta (IFN)-beta ( $\beta$ ), glatiramer acetate (GA), and siponimod are used for CIS. Short courses of high-dose corticosteroid methylprednisolone alleviate acute flare-ups of RRMS, evidencing that an inflammatory process predominates in RRMS and relapse prevention of RRMS [19,20]. Siponimod is indicated for RRMS [20]. For active RRMS monoclonal antibodies alemtuzumab and ocrelizumab, and immunomodulator dimethyl fumarate, fingolimod, and teriflunomide are prescribed besides IFN- $\beta$ and GA. For highly active RRMS, cytotoxic agents cladribine and mitoxantrone are indicated, besides immunomodulatory fingolimod, and monoclonal antibodies, natalizumab and ocrelizumab. PPMS and SPMS are characterized by a neurodegenerative process leading to a neural death [18]. An immunosuppressive monoclonal antibody ocrelizumab is indicated for treatment of PPMS [21] and diroximel fumarate, siponimod, and ofatumumab has been recently licensed for treatment of SPMS [20,22,23] (Table 1).

Table 1. Licensed disease-modifying drugs in multiple sclerosis [19-26].

\begin{tabular}{ccc}
\hline Class & Drugs & Indications \\
\hline & Interferon beta (IFN- $\beta$ ) & $\begin{array}{c}\text { CIS } \\
\text { Active RRMS }\end{array}$ \\
\cline { 2 - 3 } & Methylprednisolone & $\begin{array}{c}\text { acute flare-ups RRMS } \\
\text { Relapse prevention }\end{array}$ \\
\cline { 2 - 3 } Immunomodulators & Glatiramer acetate (GA) & $\begin{array}{c}\text { CIS } \\
\text { Active RRMS }\end{array}$ \\
\cline { 2 - 3 } & Dimethyl fumarate & Active RRMS \\
\cline { 2 - 3 } & & CIS \\
& Diroximel fumarate & RRMS \\
& & Active SPMS \\
& &
\end{tabular}




\begin{tabular}{|c|c|c|}
\hline & Fingolimod & $\begin{array}{c}\text { Active RRMS } \\
\text { High-active RRMS }\end{array}$ \\
\hline & Teriflunomide & Active RRMS \\
\hline & & CIS \\
\hline & Siponimod & RRMS \\
\hline & & SPMS \\
\hline \multirow{7}{*}{ Immunosuppressors } & Alemtuzumab & Active RRMS \\
\hline & Natalizumab & High-active RRMS \\
\hline & \multirow[t]{2}{*}{ Ocrelizumab } & $\begin{array}{c}\text { Active RRMS } \\
\text { High-active RRMS }\end{array}$ \\
\hline & & PPMS \\
\hline & \multirow{3}{*}{ Ofatumumab } & CIS \\
\hline & & RRMS \\
\hline & & Active SPMS \\
\hline \multirow{2}{*}{ Cytotoxic Agents } & Cladribine & High-active RRMS \\
\hline & Mitoxantrone & High-active RRMS \\
\hline
\end{tabular}

\section{2. Oxidative Stress}

112 A reduction oxidation (redox) reaction is a type of chemical reaction that involves the transfer of 113 electrons between two molecules. A pair of electrons transfers from a nucleophile to an electrophile, 114 forming a new covalent bond. The redox reaction is common and vital to the basic function of life disturbance of redox metabolism has been observed and plays a crucial role in pathogenesis of MS [27-29]. The serum proteomics revealed that ceruloplasmin, clusterin, apolipoprotein E, and complement C3 were up-regulated in RRMS patients, compared to healthy controls. Vitamin D-binding protein showed a progressive trend of oxidation and the increased oxidation of apolipoprotein A-IV in progression from remission to relapse of MS [30]. CSF samples of patients in a remission stage of RRMS showed higher purine oxidation product uric acid, reduced antioxidant, and increased intrathecal synthesis of IgG [31]. The observations suggest the presence of redox metabolism disturbance and involvement of inflammatory process in RRMS. Furthermore, higher serum alpha $(\alpha)$-tocopherol levels were associated with reduced T1 gadolinium $\left(\mathrm{Gd}^{+}\right)$-enhancing lesions and subsequent T2 lesions in MRI of RRMS patients on IFN- $\beta$. Antioxidant glutathione (GSH) mapping showed lower GSH concentrations in the frontoparietal region of patients suffered from PPMS and SPMS than RRMS and no significant difference between those of RRMS and controls. Thus, the oxidative stress in CNS was linked to neurodegeneration in progressive types of MS [32].

This review article reviewed participants of redox homeostasis including reactive chemical species, oxidative and antioxidative enzymes, and resulting degradation products all of which serve as evidence of biochemical assaults and tissue injuries under redox disequilibrium. A literature search was employed in PubMed/MEDLINE and Google Scholar, using appropriate search terms such as "reactive oxygen species", "oxidative stress", "redox", "biomarker", "neurodegenerative disease", "inflammation", "neurodegeneration", and/or "multiple sclerosis". Alterations of redox components in MS in general, phase-, and treatment-specific components were reviewed in search of a potential diagnostic, prognostic, predictive, and/or therapeutic redox biomarker. Finally, monitoring different redox components including oxidative enzymes, antioxidative enzymes and degradation products during the disease progression helps evaluate the redox status of MS patients, thus expediting building the most proper personalized treatment plans for MS patients [33]. 
115

116

117

118

119

120

121

122

123

124

125

126

such as cellular respiration in which sugar is oxidized to release energy which is stored in ATP. Redox metabolisms constitute multiple metabolic pathways involved in the series of redox chemical reactions indispensable for sustaining life and, at same time, engaged in removal of electrophilic oxidative species and other harmful nucleophiles. The dynamic activities range from a single electron transfer, enzyme reaction, chemical reaction cascade, to signaling in cells, tissues, organ systems, and whole organismal levels [34]. Oxidative stress is a state caused by an imbalance between the relative levels of production of reactive oxidizing metabolites and their elimination by the enzymatic or non-enzymatic antioxidant system. The oxidative state is induced by oxidative stressors either derived from xenobiotics or produced from the activities of oxidative enzymes and essential cellular constituents [35] (Figure 1 (a)). Oxidative stressors are linked to ageing process, neurologic disease, and psychiatric disorders including Alzheimer's disease (AD), Parkinson's disease (PD), MS, amyotrophic lateral sclerosis (ALS), and depression [36-40].

(a) Oxidative Stressors

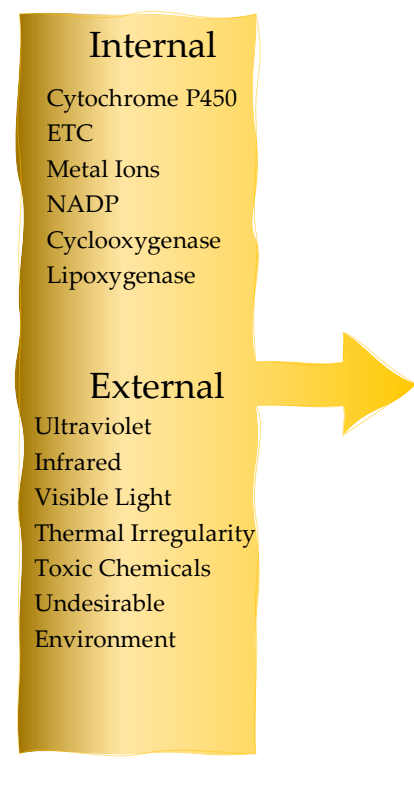

\section{(b) Reductive Stressors}

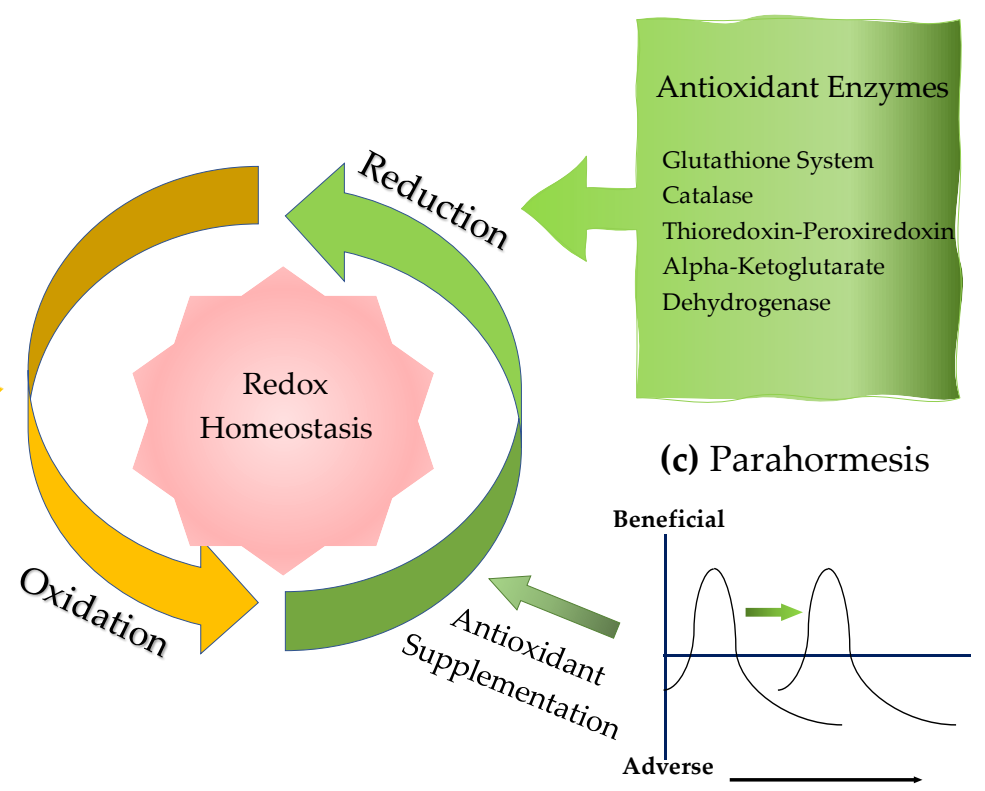

127

128

129

130

131

132

133

134

\section{5}

136

137

138

139

140

141

142

143

Figure 1. Redox homeostasis and antioxidant supplementation. (a) Oxidative stressors comprise of external and internal stressors, exerting oxidative chemical reactions in organism. Oxidation is an indispensable bioenergetic process to sustain life. (b). Reductive stressors are products of antioxidative enzymes that generate antioxidants in response to regular oxidation activity and increased oxidative stress. (c) Antioxidant supplementation attempts to shift the biphasic response from adverse to beneficial phase to maintain nucleophilic tone. This mechanism is called parahormesis.

\subsection{Endogenous oxidative stressors: oxidative enzymes and reactive species}

Endogenous oxidative stressors are produced from cellular activities of cytosolic xanthine dehydrogenase (XDH), membrane-bound nicotinamide adenine dinucleotide phosphate (NADPH) oxidase, inflammatory lipoxygenase (LOX) and cyclooxygenase (COX), phagocytic myeloperoxidase (MPO) in respiratory burst, a second messenger nitrogen oxide (NO)-producing nitric oxide synthetase (NOS), mitochondrial and lysosomal electron transfer chain (ETC) enzymes, among others. Transition metals such as iron $\left(\mathrm{Fe}^{2+}\right)$ and copper $\left(\mathrm{Cu}^{+}\right)$also play a crucial role in the formation of oxidative stressors via the Fenton reaction [41].

\subsubsection{Oxidative enzymes generating reactive oxygen species}


144

145

146

147

148

149

150

151

152

153

154

155

Reactive oxygen species (ROS) include several free radicals such as superoxide $\left(\mathrm{O}_{2^{-}}\right)$and hydroxyl radical $\left(\mathrm{OH}^{\bullet}\right)$ and nonradical molecules such as hydrogen peroxide $\left(\mathrm{H}_{2} \mathrm{O}_{2}\right)$ and organic hydroperoxide $(\mathrm{ROOH})$ (Table 1$)$. ROS are produced in endogenously in the cytosol, the plasma membrane, the membranes of mitochondria and endoplasmic reticulum, peroxisomes, and phagocytic cells [42,43] (Figure 2). ROS is difficult for direct measurement in biological tissues due to its highly reactivity and short life.

Table 2. Reactive chemical species. During regular cellular activity living cells generate numerous reactive chemical species containing oxygen, nitrogen, sulfur, carbonyl, halogen, or selenium. Reactive sulfur species can contain thiols or nitrothiols. Free radicals possess at least one unpaired electron that makes highly reactive and short-lived. Nonradicals are oxidizing chemicals or easily converted to free radicals. Superoxide, reactive sulfur species, or reactive selenium species can be reducing agents as reactive nucleophilic species.

\begin{tabular}{|c|c|}
\hline & Reactive Chemical Species \\
\hline \multirow{5}{*}{$\begin{array}{l}\text { Reactive Oxygen Species } \\
\text { (ROS) }\end{array}$} & Free Radicals \\
\hline & Superoxide anion $\left(\mathrm{O}_{2^{-}}\right)$, Hydroxyl radical $\left(\mathrm{OH}^{\bullet}\right)$, \\
\hline & Alkoxyl radical (RO•), Peroxyl radical (ROO•) \\
\hline & Nonradicals \\
\hline & $\begin{array}{l}\text { Hydrogen peroxide }\left(\mathbf{H}_{2} \mathbf{O}_{2}\right) \text {, Organic hydroperoxide }(\mathbf{R O O H}) \text {, } \\
\text { Organic peroxide }(\mathbf{R O O R}) \text {, Singlet oxygen }\left(\mathbf{O}_{2} \mathbf{L}_{\mathbf{g}}\right) \text {. Ozone }\left(\mathbf{O}_{3}\right)\end{array}$ \\
\hline \multirow{6}{*}{$\begin{array}{l}\text { Reactive Nitrogen Species } \\
\text { (RNS) }\end{array}$} & Free Radicals \\
\hline & Nitric oxide radical $\left(\mathrm{NO}^{\bullet}\right)$, Nitrogen dioxide radical $\left(\mathrm{NO}_{2}{ }^{\cdot}\right)$ \\
\hline & Nonradicals \\
\hline & Nitrite $\left(\mathrm{NO}_{2}{ }^{-}\right)$, Nitrate $\left(\mathrm{NO}_{3}{ }^{-}\right)$, Nitroxyl anion $\left(\mathbf{N O}^{-}\right)$, Nitrosyl cation \\
\hline & Nitrosoneroxycarbonate $\left(\mathrm{ONOOCO}_{2}^{-}\right)$Dinitrogen trioxide $\left(\mathrm{N}_{2} \mathrm{O}_{3}\right)$ \\
\hline & Dinitrogen tetraoxide $\left(\mathrm{N}_{2} \mathrm{O}_{4}\right)$, Nitryl chloride $\left(\mathrm{NClO}_{2}\right)$ \\
\hline \multirow{10}{*}{$\begin{array}{l}\text { Reactive Sulfur Species } \\
\text { (RSN) }\end{array}$} & Free radicals \\
\hline & Thiyl radical (RS•), Peroxysulphenyl radical (RSOO•) \\
\hline & $\underline{\text { Nonradicals }}$ \\
\hline & Hydrogen sulfide $\left(\mathbf{H}_{\mathbf{2}} \mathbf{S}\right)$, Thiolate anion $\left(\mathbf{R S}^{-}\right)$, Thiol $(\mathbf{R S H})$, \\
\hline & Hydropersulfide (RSSH), Disulfide (RSSR), Hydropolysulfide \\
\hline & $\left(\mathbf{R S S}_{\mathbf{n}} \mathbf{H}\right)$, Dialkyl polysulfide (RSSnR), Polysulfide $\left(\mathbf{H}_{2} \mathbf{S x}\right)$, Sulfenate \\
\hline & $\left(\mathrm{RSO}^{-}\right)$, Sulfinate $\left(\mathrm{RSO}_{2}{ }^{-}\right)$, Sulfonate $\left(\mathrm{RSO}_{3}{ }^{-}\right)$, Thiosulmonate \\
\hline & $\left(\mathrm{S}_{2} \mathrm{O}_{3^{2-}}\right)$, Sulfite $\left(\mathrm{RS}_{2} \mathrm{O}_{3^{2-}}\right)$, Sulfate $\left(\mathrm{SO}_{4}{ }^{2-}\right)$, Thiosulfinate $\left(\mathrm{C}_{6} \mathrm{H}_{10} \mathrm{OS}_{2}\right)$ \\
\hline & S-nitrosothiols (RSNOs), \\
\hline & $\begin{array}{l}\text { Nitrosopersulfide }\left(\text { SSNO}^{-}\right) \text {, Dinitrosylated sulfite adduct } \\
\text { (SULFI/NO) }\end{array}$ \\
\hline
\end{tabular}

\section{Nonradicals}

Reactive Carbonyl Species
(RCS)

Acetaldehyde $\left(\mathrm{CH}_{3} \mathrm{CHO}\right)$, Acrolein (Proponel ${ }^{+}: \mathrm{C}_{3} \mathrm{H}_{4} \mathrm{O}$ ),

Methylglyoxal 4-Hydroxy-nonenal $\left(\mathrm{C}_{9} \mathrm{H}_{16} \mathrm{O}_{2}\right)$, 3-Deoxyglucosone

$\left(\mathrm{C}_{6} \mathrm{H}_{10} \mathrm{O}_{5}\right)$, Glyoxal $\left(\mathrm{C}_{2} \mathrm{H}_{2} \mathrm{O}_{2}\right)$, Methylgyoxal $\left(\mathrm{C}_{3} \mathrm{H}_{4} \mathrm{O}_{2}\right)$, Electronically excited triplet carbonyls $\left({ }^{3} \mathrm{~L}=\mathbf{O}^{*}\right)$

\section{Free radicals}

Reactive Halogen species (RHS)
Atomic chlorine $\left(\mathrm{Cl}^{\bullet}\right)$, Atomic bromine $\left(\mathrm{Br}^{*}\right)$

\section{Nonradicals}

Hypochlorite $\left(\mathbf{O C l}^{-}\right)$, Chloramines (RNHCl), Hypobromite ( $\mathbf{O B r}-$, Hypoiodite (IO-), Hypohalogenite ( $\mathbf{X O}^{-} ; \mathbf{X}=\mathbf{F}, \mathbf{C l}, \mathbf{B r}$, or I)

\section{Nonradicals}

Reactive Selenium Species (RSeS)
Selenite $\left(\mathrm{O}_{3} \mathrm{Se}^{-2}\right)$, Selenate $\left(\mathrm{SeO}_{4}{ }^{2-}\right)$, Selenocysteine $\left(\mathrm{C}_{3} \mathrm{H}_{7} \mathrm{NO}_{2} \mathrm{Se}\right)$, Selenomethionine $\left(\mathrm{C}_{5} \mathrm{H}_{11} \mathrm{NO}_{2} \mathrm{Se}\right)$ 


\section{Free radicals}

\section{Reactive Nucleophilic Species}

\section{Noneradicals}

Hydrogen sulfide $\left(\mathbf{H}_{2} \mathbf{S}\right)$, Thiolate (RS-), Hydropersulfide (RSS-),

Disulfide (RSSR), Selenite $\left(\mathrm{O}_{3} \mathrm{Se}^{-2}\right)$, Selenate $\left(\mathrm{SeO}_{4}{ }^{2-}\right)$, Selenocysteine $\left(\mathrm{C}_{3} \mathrm{H}_{7} \mathrm{NO}_{2} \mathrm{Se}\right)$, Selenomethionine $\left(\mathrm{C}_{5} \mathrm{H}_{11} \mathrm{NO}_{2} \mathrm{Se}\right)$

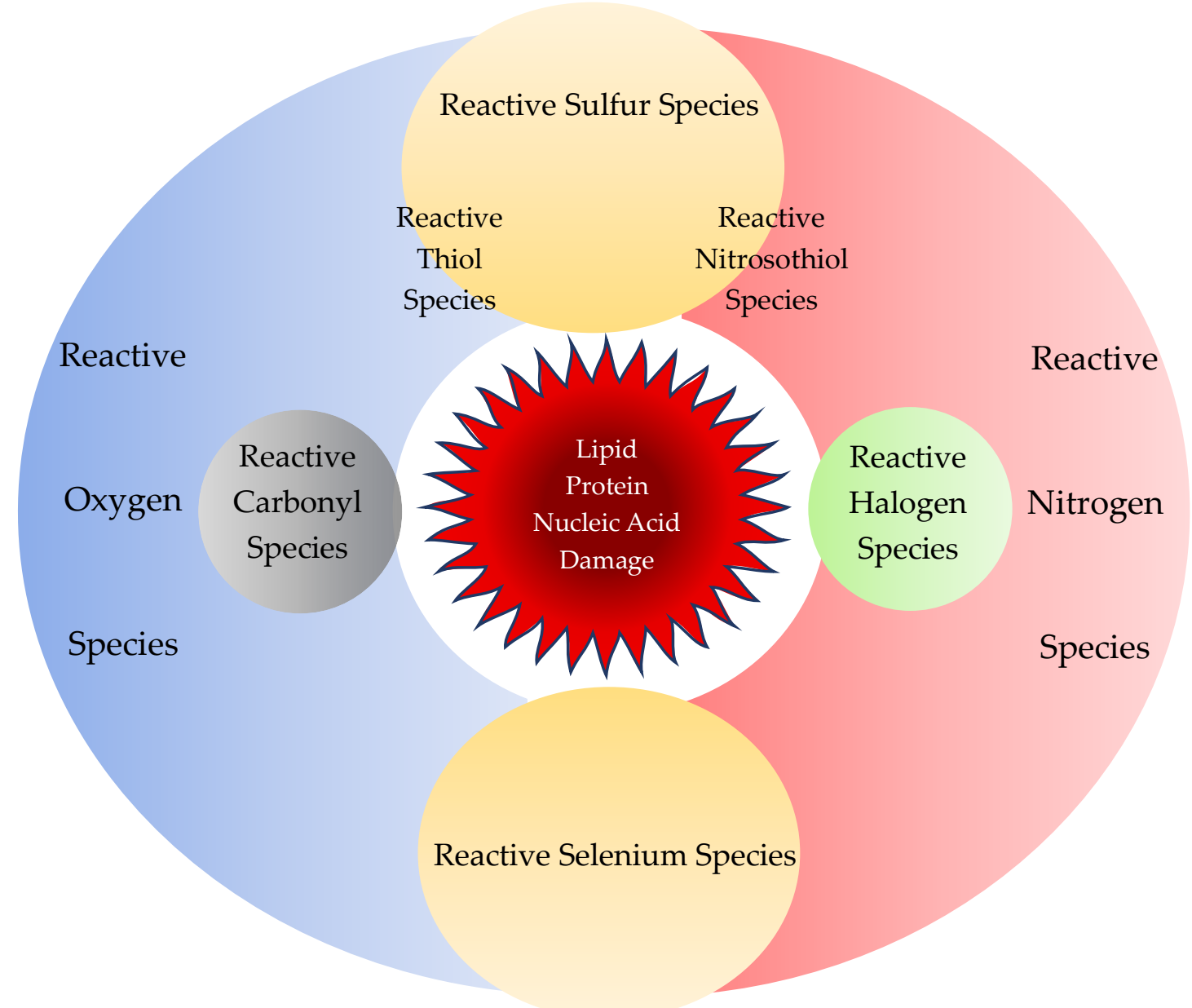

Figure 2. Reactive Chemical Species. Reactive chemical species comprise of not only reactive oxygen species and reactive nitrogen species, but also reactive sulfur, carbonyl, halogen, and selenium species. Sulfur reacts with oxygen or nitrogen to form reactive thiol or nitrosothiol species, respectively. All reactive chemical species react in concert during regular cellular activity but may cause oxidative stress to damage cellular components such as proteins, lipids, and nucleic acids.

In the cytosol, ROS can be generated by soluble intercellular components such as catecholamines, hydroquinones, flavins and thiols (RSHs) which undergo reduction reactions [44]. The cytosolic enzyme XDH normally catalyzes xanthine, $\mathrm{NAD}^{+}$and water $\left(\mathrm{H}_{2} \mathrm{O}\right)$ to urate, reduced form of $\mathrm{NAD}^{+}, \mathrm{NADH}$ and hydrogen ion $\left(\mathrm{H}^{+}\right)$. Reversible oxidation of cysteine residues or irreversible $\mathrm{Ca}^{2+}$-stimulated proteolysis converts $\mathrm{XDH}$ to xanthine oxidase $(\mathrm{XO})$ that transfers electrons to molecular oxygen $\left(\mathrm{O}_{2}\right)$, producing superoxide $\left(\mathrm{O}_{2}^{-\bullet}\right)$ during xanthine or hypoxanthine oxidation [45]. The serum levels of uric acid, a major endogenous antioxidant was measured in patients with PPMM, RRMM, and SPMM. The uric acid levels were significantly lower in active MS than inactive MS, and the uric acid levels were independently correlated with gender, disease 
172

173

174

Table 3. Oxidative stress biomarkers of multiple sclerosis. The redox status can be monitored by the activities of oxidative and antioxidative enzymes and the presence of degradation products derived from cellular components. $\uparrow$ : increase, $\downarrow$ : decrease, -: unknown.

\begin{tabular}{|c|c|c|c|c|c|}
\hline \multirow{2}{*}{\multicolumn{2}{|c|}{ Classes }} & \multirow{2}{*}{ Types } & \multicolumn{2}{|c|}{ Human Samples } & \multirow{2}{*}{ Reference } \\
\hline & & & Blood & CSF & \\
\hline \multicolumn{2}{|c|}{ Reactive Species } & Reactive Nitrogen Species & $\uparrow$ & $\uparrow$ & [79] \\
\hline \multirow{6}{*}{\multicolumn{2}{|c|}{ Oxidative Enzymes }} & $\begin{array}{c}\text { Xanthine Dehydrogenase } \\
\text { (XHD) }\end{array}$ & $\downarrow$ & - & \\
\hline & & Nicotinamide Adenine & & & \\
\hline & & $\begin{array}{l}\text { Dinucleotide Phosphate } \\
\text { (NADPH) Oxidase }\end{array}$ & $\uparrow \downarrow$ & & [48] \\
\hline & & Superoxide Dismutase (SOD) & $\uparrow$ & $\downarrow$ & [62-65] \\
\hline & & $\begin{array}{l}\text { Inducible Nitric Oxide } \\
\text { Synthase ( } i \text { NOS) }\end{array}$ & $\uparrow$ & $\uparrow$ & {$[18,95-97]$} \\
\hline & & Myeloperoxidase (MPO) & mixed & $?$ & [49] \\
\hline \multirow{7}{*}{\multicolumn{2}{|c|}{ Antioxidative Enzymes }} & Glutathione Peroxidase (GPx) & $\begin{array}{c}\uparrow \text { (relapse) } \\
\downarrow \\
\text { (remission) }\end{array}$ & $\downarrow$ & $\begin{array}{c}{[127-129,146-} \\
148]\end{array}$ \\
\hline & & Glutathione Reductase (GSR) & - & $\uparrow$ & {$[148,149]$} \\
\hline & & Catalase & $\begin{array}{c}\downarrow \\
\text { (granulocyte) }\end{array}$ & $?$ & {$[148,149]$} \\
\hline & & $\begin{array}{c}\text { Xanthine oxidase (XO)-Uric } \\
\text { Acid }\end{array}$ & $\downarrow$ & - & [46] \\
\hline & & $\begin{array}{l}\text { Nuclear Factor Erythroid } \\
\text { 2-Related Factor (Nrf2) }\end{array}$ & $\uparrow$ & - & [65] \\
\hline & & $\begin{array}{l}\text { Peroxisome } \\
\text { proliferator-activated } \\
\text { receptors (PPARs) }\end{array}$ & - & $\uparrow$ & [160] \\
\hline & & $\begin{array}{c}\text { Peroxisome } \\
\text { proliferator-activated } \\
\text { receptor gamma coactivator } \\
\text { 1-alpha }(\text { PGC- } 1 \alpha)\end{array}$ & $\downarrow$ & - & [166] \\
\hline \multirow{13}{*}{$\begin{array}{l}\text { Degradation } \\
\text { Products }\end{array}$} & \multirow{6}{*}{ Protein } & Protein carbonyls & $\uparrow$ & - & $\begin{array}{c}{[176-178,184-} \\
187]\end{array}$ \\
\hline & & 3-nitrotyrosin (3-NO-Tyr) & $\uparrow$ & - & [183-186] \\
\hline & & Protein glutathionylation & $?$ & - & [189] \\
\hline & & Dityrosine & $\uparrow$ & - & [180] \\
\hline & & $\begin{array}{l}\text { Advanced oxidation protein } \\
\text { products (AOPPs) }\end{array}$ & $\uparrow$ & - & {$[62,180,193]$} \\
\hline & & $\begin{array}{l}\text { Advanced glycation end } \\
\text { products (AGEs) }\end{array}$ & $\uparrow$ & $\uparrow$ & {$[180,193]$} \\
\hline & $\begin{array}{l}\text { Amino } \\
\text { acids }\end{array}$ & $\begin{array}{c}\text { Asymmetric } \\
\text { dimethylarginine (ADMA) }\end{array}$ & $\downarrow$ & - & [195] \\
\hline & \multirow{5}{*}{ Lipid } & F2-isoprostane (F2-isoP) & $\uparrow$ & $\uparrow$ & [198-202] \\
\hline & & Malondialdehyde (MDA) & mixed & $\uparrow$ & $\begin{array}{c}{[61,80,148} \\
152,203]\end{array}$ \\
\hline & & 4-hydroxynonenal (4-HNE) & $?$ & $\uparrow$ & [204] \\
\hline & & $\begin{array}{l}\text { Hydroxyoctadecadienoic acid } \\
\text { (HODE) }\end{array}$ & $\uparrow$ & $\uparrow$ & [205] \\
\hline & & Oxysterol & $\uparrow$ or $\downarrow$ & $\uparrow$ & [207] \\
\hline & DNA & 8-dihydro-2' & $\uparrow$ & $?$ & {$[127]$} \\
\hline
\end{tabular}


deoxyguanosine (8-oxodG)

175

176

177

178

179

180

181

182

183

184

185

186

187

188

189

190

191

192

193

194

195

196

197

198

199

200

201

202

203

204

205

206

207

208

209

210

211

212

213

214

215

216

217

218

219

The plasma membrane is a network of phospholipid bilayer and integral proteins, which protects the cellular organelles from the outer environment and responsible for several cellular functions such as cell adhesion, ion transport, cell signaling and phagocytosis. The main ROS of the plasma membrane is superoxide $\left(\mathrm{O}_{2^{-}}^{-}\right)$produced by the membrane-bound enzyme nicotinamide adenine dinucleotide phosphate oxidase (NOX) which is composed of two membrane proteins, three cytosolic proteins, and a small GTP-binding protein $[47,48]$. The expression of NOX isoform NOX5 was significantly increased, but the expression NOX4 was significantly decreased in serum of RRMS patients, suggesting differential NOX isoform expression contributes to OS-associated vascular changes in MS [49]. ROS is also produced by COX and LOX which convert arachidonic acid to prostaglandins, thromboxanes, and leukotrienes. Phospholipase $\mathrm{A}_{2}$ generates ROS during arachidonic acid oxidation [50]. In the presence of transition metal ions such as $\mathrm{Fe}^{2+}$ and $\mathrm{Cu}^{+}$, hydrogen peroxide $\left(\mathrm{H}_{2} \mathrm{O}_{2}\right)$, organic hydroperoxide $(\mathrm{ROOH})$ and organic peroxide (ROOR) produce hydroxyl $\left(\mathrm{OH}^{*}\right)$, alkoxyl $(\mathrm{RO} \cdot)$ and peroxyl radical (ROO•), respectively [51]. (Table 3).

Superoxide dismutase (SOD) catalyzes the disproportionation of two superoxide $\left(\mathrm{O}_{2^{-}}\right)$into molecular oxygen $\left(\mathrm{O}_{2}\right)$ and hydrogen peroxide $\left(\mathrm{H}_{2} \mathrm{O}_{2}\right)$. These enzymes are present in almost all aerobic cells and in extracellular fluids. SODs contain metal ion cofactors that, depending on the isozyme, can be copper, zinc, manganese, or iron [52,53]. There are three isozymes in humans. Dimeric copper- and zinc-coordinated SOD1 is in the cytoplasm; tetrameric manganese-coordinated SOD2 is confined to the mitochondria; tetrameric copper- and zinc-coordinated SOD3 is extracellular [54]. The mitochondrial ROS production takes place at four protein complexes, ubiquinone, and cytochrome $\mathrm{c}$ of the ETC, embedded in the inner membrane of the mitochondria [55]. The Complexes I/III/IV utilize NADH as the substrate, while Complexes II/III/IV use succinic acid. The complex II is also glycerol 3-phosphate dependent. The primary mitochondrial ROS is superoxide $\left(\mathrm{O}_{2}^{-\bullet}\right)$ that is converted by mitochondrial SOD into hydrogen peroxide $\left(\mathrm{H}_{2} \mathrm{O}_{2}\right)$, which can be turned into hydroxyl $\left(\mathrm{OH}^{\bullet}\right)$ via the Fenton reaction [56]. The Complex I and III release superoxide $\left(\mathrm{O}_{2}^{-\bullet}\right)$ into the mitochondrial matrix where it can damage the mitochondrial DNA, while the Complex III also releases superoxide $\left(\mathrm{O}_{2}^{-\bullet}\right)$ into the intermembrane space where it is accessible to the cytosol [57]. Reduced levels of antioxidant $\alpha$-tocopherol was observed in blood of patients with Leber's hereditary optic neuropathy which is caused by mitochondrial mutation of the Complex I, suggesting that oxidative load was elevated, and antioxidant capacity was compromised [58]. Other mitochondrial enzymes which contribute to hydrogen peroxide $\left(\mathrm{H}_{2} \mathrm{O}_{2}\right)$ production are monoamine oxidases, dihydroorotate dehydrogenase, $\alpha$-glycerophosphate dehydrogenase and $\alpha$-ketoglutarate dehydrogenase ( $\alpha$-KGDH) complex. Succinate dehydrogenase also generate ROS [59].

Significantly higher mean activity of SOD in erythrocyte lysates was reported in RRMS than controls. Interestingly, the SOD activity of CIS was higher than that of RRMS [60]. The SOD activity was significantly lower in the erythrocyte lysates of RRSM patients upon relapse than controls but increased following the intravenous administration of corticosteroid methylprednisolone and remained higher during remission period than controls. The mean SOD activity of serum/plasma samples was significantly higher in RRMS compared to control groups [61]. However, platelet SOD1 and SOD2 activity was unchanged in MS patients [62]. In contrast SOD activity was observed significant low in CSF of CIS and RRMS patients despite significantly high activity of plasma SOD. There were negative correlations between the erythrocyte SOD activity and disease duration and expanded disability status scale (EDSS) in CIS and RRMS, between the erythrocyte SOD activity and $\mathrm{Gd}^{+}$enhancement lesion volume in CIS patients [63]. These findings suggest SOD activity as possible diagnostic and prognostic marker (Table 3, Table 4).

Table 4. Possible redox biomarkers in multiple sclerosis. Reactive chemical species, oxidative enzymes, antioxidants, antioxidative enzymes, degradation products, and end products are potential biomarkers for multiple sclerosis (MS). Diagnostic biomarkers allow early detection and secondary prevention; prognostic biomarkers suggest the likely clinical course; predictive biomarkers predict the response of MS patients to a specific therapy; and therapeutic biomarkers indicate a target for 
therapy. CIS: clinically isolated syndrome, PPMS: primary progressive MS; RRMS: relapsing-remitting MS, SPMS: secondary progressive MS, mixedMM: mixed population of MS.

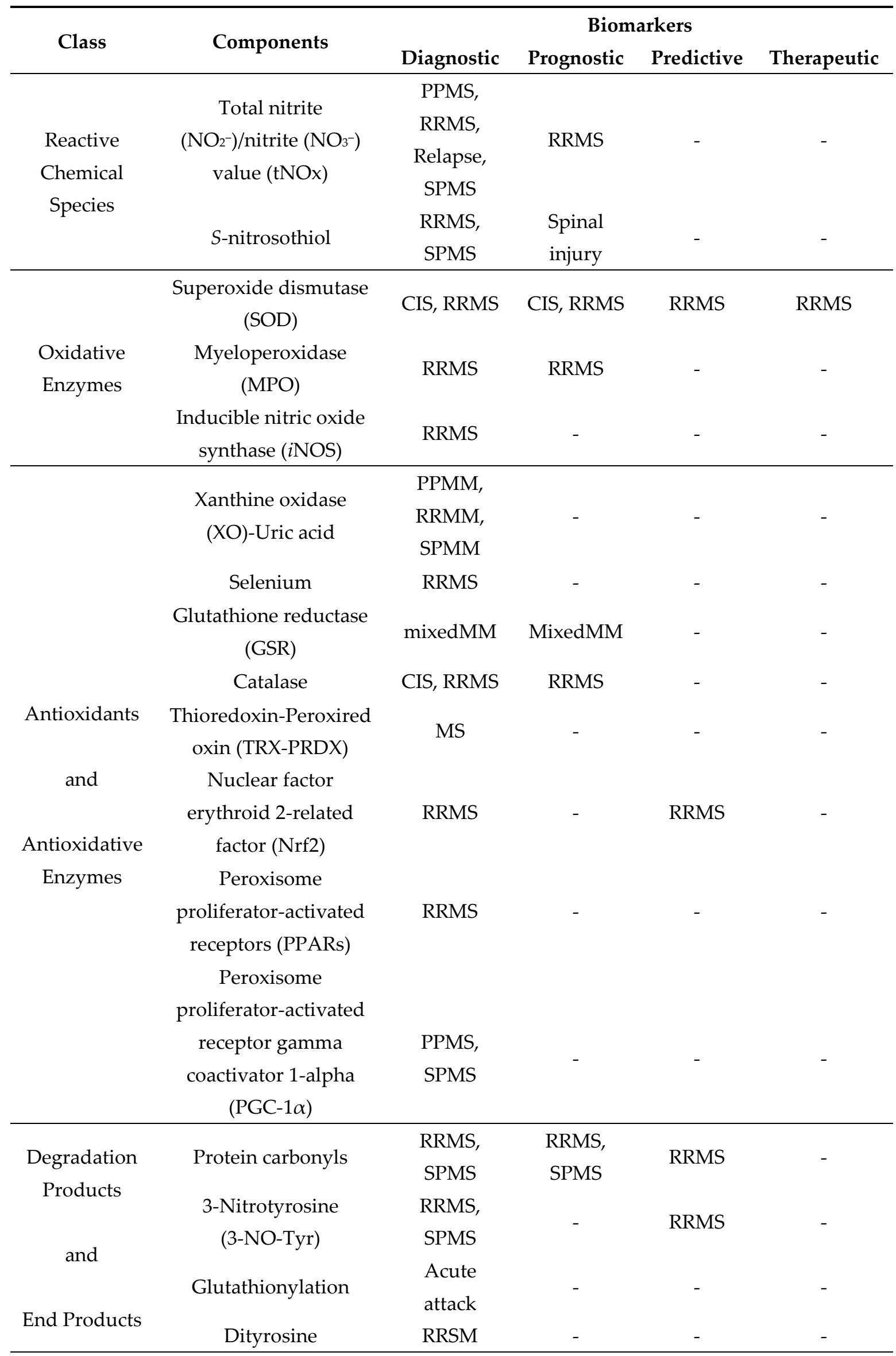




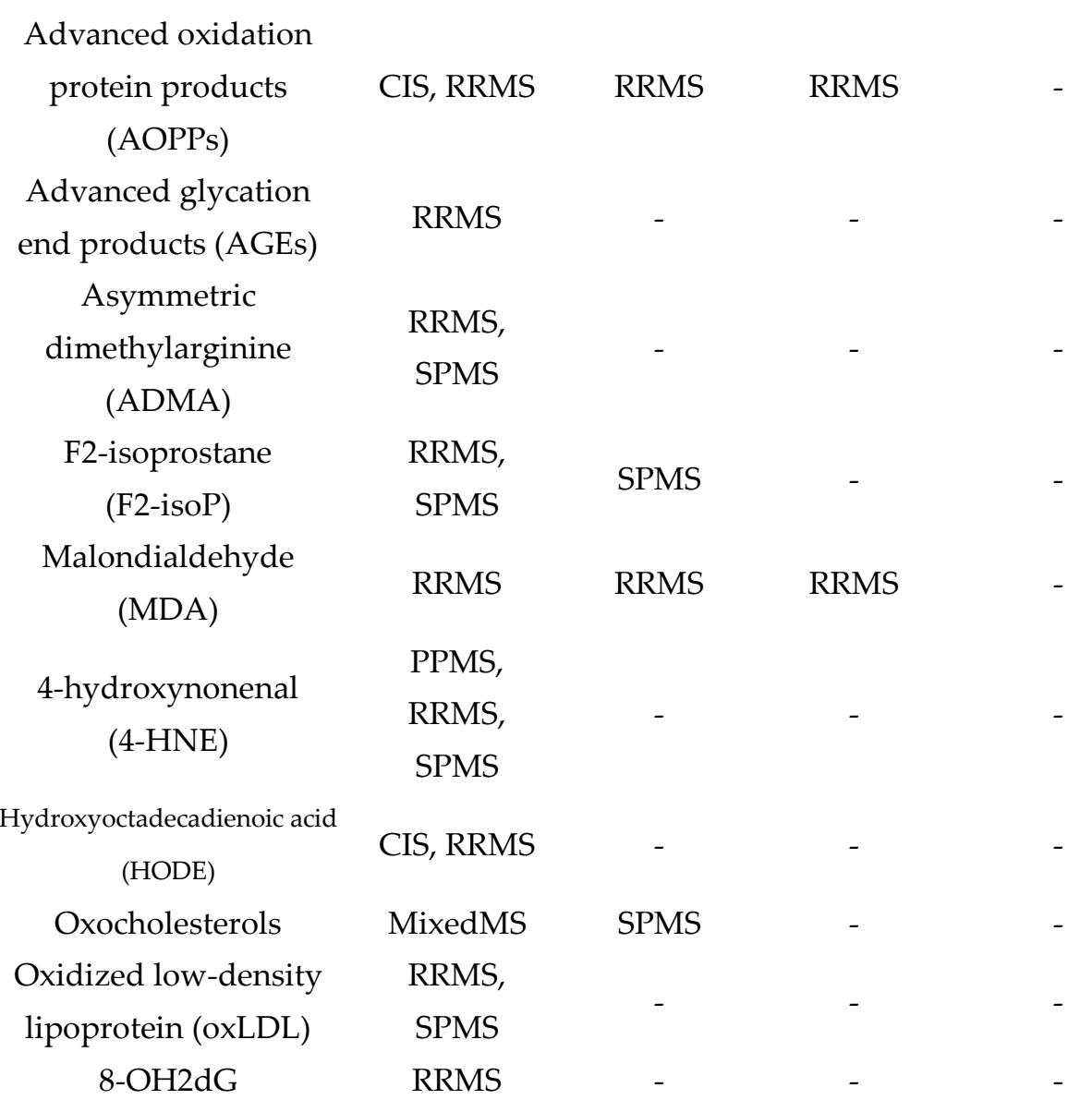

The peripheral blood mononuclear cells (PBMCs) SOD1 proteins and mRNA expression were significantly lower in RRMS patients than controls and became significantly elevated following IFN- $\beta 1 \mathrm{~b}$ treatment than the baseline [64]. These studies suggest SOD as a potential therapeutic biomarker (Table 4). However, the erythrocyte SOD activity remained unchanged following the treatment of natalizumab, a humanized monoclonal antibody against the cell adhesion molecule $\alpha 4$-integrin. But levels of carbonylated protein and oxidized guanosine were reduced [65].

In the inner membrane of mitochondria and the endoplasmic reticulum, a heme-containing monooxygenase cytochrome P450 (CYP) enzymes are responsible for oxidizing steroids, cholesterols, and fatty acids. The CYPs forms ROS superoxide $\left(\mathrm{O}_{2}^{-\bullet}\right)$ and hydrogen peroxide $(\mathrm{ROOH})$ by substrate cycling [66]. Protonation of hydrogen peroxide (ROOH) forms hydrogen peroxide $\left(\mathrm{H}_{2} \mathrm{O}_{2}\right)$ which, furthermore, cleaves into hydroxy radicals $\left(\mathrm{OH}^{\bullet}\right)$. The redox cycling produces free radical semiquinone from quinoid substrates [67]. In the mitochondrial transport chain, flavoprotein reductase forms ROS by direct reduction of $\mathrm{O}_{2}$ and via the mediation of quinones. [68]. Superoxide $\left(\mathrm{O}_{2}^{-\bullet}\right)$ is produced by $\mathrm{XO}$ in the reperfusion phase of ischemia, LOX, COX, and NADPH-dependent oxidase [69]. In the endoplasmic reticulum NADH cytochrome b5 reductase can leak electrons to molecular oxygen $\left(\mathrm{O}_{2}\right)$ to generate superoxide $\left(\mathrm{O}_{2}^{-\bullet}\right)$ during the NADPH-dependent oxidation of xenobiotics [70].

Most enzymes in the peroxisomes produce ROS during the catalysis of fatty acid $\alpha$ - and $\beta$ oxidation, amino acid and glyoxylate metabolism, and synthesis of lipidic compounds. A large fraction of hydrogen peroxide $\left(\mathrm{H}_{2} \mathrm{O}_{2}\right)$ generated inside peroxisomes was observed to penetrate the peroxisomal membrane and diffuse to the surrounding media [71]. The peroxide can diffuse through the channel formed by the peroxisomal membrane protein Pxmp2 and hydrogen peroxide $\left(\mathrm{H}_{2} \mathrm{O}_{2}\right)$ generated by the peroxisomal urate oxidase can release through crystalloid core tubules into the cytosol [72]. Meanwhile, peroxisomes also possess protective mechanisms to counteract oxidative stress and maintain redox balance. Reduction in peroxisomal gene and protein expression was observed in MS grey matter [73]. 
The lysosomal ETC plays a central role to support the positive proton gradient to maintain an optimal $\mathrm{pH}$ of the acid hydrolases [74]. The ETC is made up of a flavin-adenine dinucleotide, a b-type cytochrome and ubiquinone with the donor NADH and ending to acceptor molecular oxygen $\left(\mathrm{O}_{2}\right)$, transferring three electrons. Superoxide $\left(\mathrm{O}_{2}^{-\bullet}\right)$ is possibly produced in the acidic environment which favors dismutation of hydrogen peroxide $\left(\mathrm{H}_{2} \mathrm{O}_{2}\right)$ into hydroxy radical $\left(\mathrm{OH}^{\bullet}\right)$ by ferrous iron [75]. Furthermore, ozone $\left(\mathrm{O}_{3}\right)$ and ozone-like oxidants are generated from singlet oxygen $\left(\mathrm{O}_{2}{ }^{1} \Delta_{\mathrm{g}}\right)$ catalyzed by antibody or amino acid. Ozone $\left(\mathrm{O}_{3}\right)$ reacts with superoxide anion $\left(\mathrm{O}_{2}^{-\bullet}\right)$ to form hydrogen peroxide $\left(\mathrm{H}_{2} \mathrm{O}_{2}\right)$ in the presence of $\mathrm{Fe}^{+2}$ [76].

\subsubsection{Oxidative enzymes generating reactive nitrogen species}

Reactive nitrogen species (RNS) are a group of nitrogen-congaing molecules including free radicals, nitric oxide $(\mathrm{NO})$, and nitrogen dioxide $\left(\mathrm{NO}_{2}\right)$. Free radicals are nitric oxide $(\mathrm{NO} \bullet)$ and nitrogen dioxide $\left(\mathrm{NO}_{2}{ }^{\circ}\right)$ radicals, while nonradicals are nitrite $\left(\mathrm{NO}_{2}{ }^{-}\right)$and nitrate $\left(\mathrm{NO}_{3}{ }^{-}\right)$, among others (Table 2). RNS are derived from nitric oxide (NO) and superoxide anion $\left(\mathrm{O}_{2}^{-\bullet}\right)$ produced by nitric oxide synthetase 2 (NOS2), NADPH oxidase, XO, LOX, and COX, among others [77,78]. At physiological concentrations, a gaseous molecule nitric oxide (NO) is a second messenger involved in blood pressure regulation, smooth muscle relaxation, defense mechanisms, immune regulation, and neurotransmission contributing the function of memory and learning [79].

Cross-sectional studies showed that the levels of nitric oxide metabolites nitrite $\left(\mathrm{NO}_{2}{ }^{-}\right)$and nitrite $\left(\mathrm{NO}_{3}{ }^{-}\right)$, measured as a total value (tNOx) are significant higher in plasma or serum of patients with RRMS [80,817]. A longitudinal study revealed that higher serum tNOx is significantly correlated with relapsing rate, suggesting prognostic biomarker of NOS [82]. Many studies of CSF samples reported significantly higher levels of tNOx in RRMS and PPMS, compared to healthy controls [83,84]. A study observed significantly higher levels of CSF tNOx in RRMS than SPMS, suggesting an inflammatory role of RNS [85]. Significantly higher levels of CSF tNOx were reported in patients with acute relapsing phase of RRMS than those with stable remitting phase of RRMS $[86,87]$ (Table 3, Table 4).

In cGMP-dependent pathways, nitric oxide radical (NO•) generated by endothelial NOS in endothelium, brain, and heart relaxes blood vessels and maintains normal blood pressure, while nitric oxide radicals ( $\mathrm{NO}^{\bullet}$ ) produced by neuronal NOS serve as a neurotransmitter to regulate blood pressure in the brain. Inducible NOS ( $i$ NOS) in macrophages and smooth muscle cells gives rise to nitric oxide radicals ( $\mathrm{NO}^{*}$ ) as in reaction to bacterial lipopolysaccharides and/or cytokines [88].

Nitric oxide radical $\left(\mathrm{NO}^{*}\right)$ is produced from the metabolism of L-arginine by NOS that converts L-arginine into L-citrulline and nitric oxide radical $(\mathrm{NO} \cdot)$ by a 5-electron oxidation of a guanidine nitrogen of L-arginine [89]. In mitochondria nitric oxide radicals $(\mathrm{NO} \bullet$ ) react with respiratory Complex III to inhibit electron transfer and facilitate superoxide anion $\left(\mathrm{O}_{2}{ }^{-}\right)$production. The nitric oxide radicals $(\mathrm{NO} \cdot)$ also compete with molecular oxygen $\left(\mathrm{O}_{2}\right)$ for the binding site at the binuclear center of cytochrome $c$ oxidoreductase, inducing a reversible inhibition of cytochrome $c$ oxidase. Nitric oxide (NO) neutralizes ROS [45]. However, RNS react with oxygen molecules $\left(\mathrm{O}_{2}\right)$ and $\mathrm{ROS}$, giving rise to a variety of nitrogen oxides (NOs) such as nitrogen dioxide radical $\left(\mathrm{NO}_{2}{ }^{\circ}\right)$, nitrogen dioxide $\left(\mathrm{NO}_{2}\right)$, dinitrogen trioxide $\left(\mathrm{N}_{2} \mathrm{O}_{3}\right)$, peroxynitrite $\left(\mathrm{ONOO}^{-}\right)$, nitrite $\left(\mathrm{NO}_{2}^{-}\right)$, and nitrate $\left(\mathrm{NO}_{3}^{-}\right)$. Higher concentrations of nitric oxide (NO) become toxic by forming nitrosothiols which oxidize tyrosine, cysteine, methionine, and GSH. In mitochondria, nitric oxide radicals (NO•) inhibit Complex I by S-nitrosation [90]. Together with other RNS this contributes the damage of cell membranes, proteins, and lipid membrane leading to the degradation of mitochondria, lysosomes, and DNA. The chain of events culminates in the inhibition of immune response and production of carcinogenic nitrosamines [91]. Nitric oxide (NO) is also involved in metal homeostasis including $\mathrm{Fe}$, $\mathrm{Cu}$, and $\mathrm{Zn}[92]$.

Highly toxic peroxynitrite $\left(\mathrm{ONOO}^{-}\right)$is formed by the reaction of nitric oxide (NO) and superoxide anions $\left(\mathrm{O}_{2}^{-\bullet}\right)$ leading to the production of more reactive compounds that oxidize methionine and tyrosine residues of proteins, lipids, and DNA. Reacting with superoxide anion $\left(\mathrm{O}_{2}^{-\bullet}\right)$, nitric oxide radicals $(\mathrm{NO} \cdot)$ form peroxynitrite which causes reversible inhibition of cellular 
respiration in the mitochondria [93]. In peroxisomes nitric oxide radicals (NO•) react with superoxide anions $\left(\mathrm{O}_{2^{-}}^{-}\right)$produced by $\mathrm{XO}$ to form peroxynitrite and hydrogen peroxides [75]. In addition, insulin resistance favors peroxintrite formation [94].

In response to bacterial lipopolysaccharides and inflammatory stimuli, $i$ NOS generates nitric oxide (NO) that protects tissue hypoxia and serves as a neurotransmitter. However, overexpression $i \mathrm{NOS}$ and subsequent increase of nitric oxide (NO) has been implicated in pathophysiology of neurodegenerative diseases including MS [79]. The $i$ NOS activity is upregulated in acute MS plaques $[19,95]$. Increased activity and expression of $i \mathrm{NOS}$ in lymphocytes were found in active relapsing phase of RRMS [96]. CSF $i$ NOS expression was shown in MS patients and mean CSF NOS activity was significantly higher, compared to controls [97] (Table 3).

\subsubsection{Reactive sulfur species}

Reactive sulfur species (RSS) are sulfur-based redox-active compounds able to oxidize or reduce biomolecules under physiological conditions, often formed by thiols (RSHs) and disulfides (RSSHs). RSS include cysteine and methionine, GSH, trypanothione, and mycothiol [98] (Table 2).

Thiyl radicals (RS•), very reactive oxidants produced in the active site of enzymes such as the ribonucleotide reductase can react with nitric oxide radicals (NO•) [99]. Thiolate ions (RS-) are better nucleophiles than alkoxides because sulfur is more polarizable than oxygen [100]. Thiol (RSH) is a metal ligand [101]. Hydrogen sulfide $\left(\mathrm{H}_{2} \mathrm{~S}\right)$ is produced from from L-cysteine by cistationine- $\gamma$-lyase. Hydrogen sulfide $\left(\mathrm{H}_{2} \mathrm{~S}\right)$ increases the activity of $\mathrm{N}$-methyl-D-aspartate receptor and $\beta$-adrenergic receptors through a cAMP-dependent protein kinase and activates NOS and the hemoxygenase favoring the formation of Nitric oxide (NO) and carbon monoxide (CO) from heme metabolism [102]. Hydrogen sulfide $\left(\mathrm{H}_{2} \mathrm{~S}\right)$ is a metal ligand that reacts with other biological electrophilic sulfur species such as hydropersulfide (RSSR) and sulfenic acid (RSOH) [103]. Cysteine residues in GSH were found to be readily oxidized by superoxide anions $\left(\mathrm{O}_{2}^{-\bullet}\right)$ to form singlet oxygen $\left(\mathrm{O}_{2}{ }^{1} \Delta_{\mathrm{g}}\right)$, glutathione disulfide (GSSG), and glutathione sulfonate $\left(\mathrm{GSO}_{3}^{-}\right)$in a reaction involved with peroxysulphenyl radical (RSOO•). This mechanism may apply to cysteine residues in proteins [104]. Hydroxyl radicals $\left(\mathrm{OH}^{*}\right)$ may also initiate the conversion of amino acids to peroxyl radicals [51]. Another reaction catalyzed by $\mathrm{XO}$ is the decomposition of S-nitrosothiols (RSNO), a RNS, to nitric oxide $(\mathrm{NO})$, which reacts with a superoxide $\left(\mathrm{O}_{2}^{-\bullet}\right)$ anion to form peroxynitrite $\left(\mathrm{ONOO}^{-}\right)$under aerobic conditions [105]. Hydropersulfide (RSSH) is a nucleophile as well as electrophilic molecule that is readily reduced to extremely potent reductant thiol (RSH). Disulfide (RSSR) is electrophilic RSS that can be reduced to thiol (RSH). Hydropolysulfide ( $\left.\mathrm{RSS}_{\mathrm{n}} \mathrm{H}\right)$ and dialkyl polysulfide (RSSnR) are like hydropersulfide (RSSH) [103]. RSS can interact with ROS, generating sulfur oxides such as peroxysulphenyl radical $\left.(\mathrm{RSOO})^{-}\right)$, sulfenate $\left(\mathrm{RSO}^{-}\right)$, sulfinate $\left(\mathrm{RSO}_{2}^{-}\right)$, sulfonate $\left(\mathrm{RSO}_{3}^{-}\right)$, thiosulmonate $\left(\mathrm{S}_{2} \mathrm{O}_{3}{ }^{2-}\right)$, and $\mathrm{SO}_{4}{ }^{2-}$ [106]. Sulfenate ( $\left.\mathrm{RSO}^{-}\right)$reacts with other thiols to give disulfides, RSSR. RSS can also interact with RNS, leading to the formation of S-N hybrid molecules such as thiazate ( $\left.\mathrm{NSO}^{-}\right)$, thionitrite (SNO-) isomers, S-nitrosothiols (RSNOs), nitrosopersulfide ( $\left.\mathrm{SSNO}^{-}\right)$, and the dinitrosylated sulfite adduct, SULFI/NO. S-nitrosothiols (RSNOs) can be reduced to thiol (RSH) and nitroxyl (HNO) [107]. XO catalyzes S-nitrosothiols (RSNOs) to nitric oxide (NO), which reacts with a superoxide $\left(\mathrm{O}_{2}^{-\bullet}\right)$ anion to form peroxynitrite $\left(\mathrm{ONOO}^{-}\right)$under aerobic conditions [89]. The properties of thiazate $\left(\mathrm{NSO}^{-}\right)$, thionitrite $\left(\mathrm{SNO}^{-}\right)$isomers, nitrosopersulfide $\left(\mathrm{SSNO}^{-}\right)$and polysulfides dinitrososulfites (Sulfi/NO) are to be determined and they appear to be a source of nitric oxide $(\mathrm{NO})$ and nitroxyl (HNO) [108-110] (Table 2).

An antioxidant $N$-acetyl cysteine administration was reported to improve cognitive functions in patients in MS and $\mathrm{N}$-acetyl cysteine supplement is under clinical trial for the treatment of fatigue in MS patients [117,112]. The levels of methionine reported mixed results. The plasma methionine levels were significantly reduced in RRMS and dietary methionine supplement was proposed for the treatment [113]. The level of methionine sulfoxide was elevated more than two-fold in CSF of MM patients and reduction of dietary methionine was reported to slow the onset and progression MM [114,115]. The levels of GSH in MS have not reached a consensus [115-117]. Trypanothione and mycothiol have not been investigated in MS. The serum S-nitrosothiol levels were increased in 
RRMS and SPMS, and selectively correlated with spinal cord injury and thus a high level of $S$-nitrosothiol is proposed to be a potential prognostic biomarker for spinal cord injury in MS [118] (Table 3,Table 4 ).

\subsubsection{Reactive carbonyl/halogen/selenium species}

Reactive carbonyl species (RCS) are metabolically generated highly reactive molecules with aldehydes and electronically excited $\left({ }^{3} \mathrm{~L}=\mathrm{O}^{*}\right)$ triplet carbonyls known for their harmful reactions to nucleic acids, proteins, and lipids [51]. In addition, RCS are considered to participate in electrophilic signaling of adaptive cell response and post-transcriptional protein modification [119]. RCS are classified into $\alpha, \beta$-unsaturated aldehydes; keto-aldehyde and di-aldehydes. In the presence of catalase and bicarbonate, $\mathrm{XO}$ was found to produce the strong one-electron oxidant carbonate radical anion from oxidation with acetaldehyde. The carbonate radical was likely produced in one of the enzyme's redox centers with a peroxymonocarbonate intermediate [45]. Self-reaction of lipid peroxyl radical (LOO•) produced by the oxidation of polyunsaturated fatty acids (PUFAs) by hydroxyl radical $(\mathrm{HO} \cdot)$ generates electronically excited triplet carbonyls $\left({ }^{3} \mathrm{~L}=\mathrm{O}^{*}\right)$ yielding to singlet oxygen $\left(\mathrm{O}_{2}{ }^{1} \Delta_{\mathrm{g}}\right)$ [47] (Table 2). RCS react with amines and thiols leading to advanced glycation end products (AGEs), biomarkers of ageing and degenerative diseases [120].

$\mathrm{MPO}$, a lysosomal heme-containing enzyme present in granulocytes and monocytes catalyzes the conversion of hypdrogen peoxide $\left(\mathrm{H}_{2} \mathrm{O}_{2}\right)$ and chloride anion $\left(\mathrm{Cl}^{-}\right)$to hypochlorous acid $(\mathrm{HClO})$ during the respiratory burst. An adipocyte producing hormone leptin stimulates the oxidative burst [121]. MPO also oxidizes tyrosine to tyrosyl radical [122]. MPO mediates protein nitrosylation, forming 3-chlorotyrosine (3-Cl-Tyr) and dityrosine crosslinks [123,124] (Table 2).

Studies on MPO activity reported mixed results. The mean MPO activity of peripheral leukocyte was observed reduced in a mixed population of MS patients, compared to controls [125]. Significantly higher serum MPO activity was measured in opticospinal phenotype (OSMS) of RRMS at relapse and remission and in conventional phenotype of RRMS at remission, compared to controls. A positive correlation was associated between Kurtzke's EDSS and MPO activity at remission of OSMS [126] (Table 4). The mean MPO activity of peripheral leukocytes was found higher, but statistically not significant in RRMS, compared to controls [127] (Table 3). No study regarding CSF MPO activity in MS was found.Selenium is an essential micronutrient with similar chemical and physical properties to sulfur, but more easily oxidized and kinetically more labile than sulfur. Selenium is a component of proteinogenic selenocysteine, naturally occurring selenomethionine and selenoproteins such as glutathione peroxidase (GPx), thioredoxin reductase (TRXR), and selenoprotein P. [128]. Reactive selenium species (RSeS) are selenium-containing inorganic and organic compounds including selenite $\left(\mathrm{O}_{3} \mathrm{Se}^{-2}\right)$, selenocysteine $\left(\mathrm{C}_{3} \mathrm{H}_{7} \mathrm{NO}_{2} \mathrm{Se}\right)$, and selenomethionine $\left(\mathrm{C}_{5} \mathrm{H}_{11} \mathrm{NO}_{2} \mathrm{Se}\right)$ [129] (Table 2). Selenium have both beneficial and harmful actions. At low concentration it works as an antioxidant, inhibiting lipid peroxidation and detoxifying ROS as a component of GPx and TRXR, while at high concentration it becomes a toxic pro-oxidant, generating ROS, inducing lipid oxidation and forming cross-linking in thioproteins [130] (Table 2). The serum selenium levels were measured significantly lower in MS patients, compared to controls, suggesting antioxidant capacity is impaired in MS [131] (Table 3).

\subsubsection{Exogenous oxidative factors}

Oxidative stressors are generated in reaction to exogenous stimuli such as pollutants, food and alcohol, cigarette smoke, heavy metals, chemotherapy, drug and xenobiotics, or radiation. Ageing becomes more susceptible to their insults. Organic solvents, organic compounds such as quinone, pesticides and heavy metals including lead, arsenic, mercury, chromium, and cadmium are common sources of oxidative stressors [41]. Ultraviolet and infrared-B radiations generate oxygen radicals endogenously [132] (Figure 1 (a)). The levels of serum arsenic, malondialdehyde (MDA), and lactate were elevated and ferric-reducing activity of plasma was reduced RRMS patients and the levels of serum lithium were significantly lower and the levels of nitric oxide (NO) were higher in RRMS 
404

405

406

407

408

409

410

411

412

413

414

415

416

patients, compared to healthy controls, suggesting environmental factors seem to play a role in pathogenesis of MS [133,134].

\section{Reductive Stress}

\subsection{Reactive nucleophilic species}

Endogenous reductive stressors include nucleophilic free radical, inorganic, and organic molecules and antioxidative enzyme. (Figure $1(\mathrm{~b})$ ). Superoxide $\left(\mathrm{O}_{2}^{-\bullet}\right)$ anion is one of reactive nucleophilic species and powerful reducing agent under physiological conditions, which initiates reaction cascades generating another ROS such as hydrogen peroxide $\left(\mathrm{H}_{2} \mathrm{O}_{2}\right)$ and sulfur dioxide $\left(\mathrm{SO}_{2}\right)$ derivatives. Hydrogen sulfide $\left(\mathrm{H}_{2} \mathrm{~S}\right)$, thiolate (RS-), hydropersulfide (RSS-) and disulfide (RSSR) are reactive nucleophilic species that can participate in nucleophilic substitution in vivo [102]. Selenium is more nucleophilic than sulfur due to its greater electron density. The selenol (RSeH) portion of selenocysteine $\left(\mathrm{C}_{3} \mathrm{H}_{7} \mathrm{NO}_{2} \mathrm{Se}\right)$ is ionized at physiological $\mathrm{pH}$, making it more nucleophilic against oxidative species $[135,136]$ (Table 2$)$.

\subsection{Antioxidative enzymes}

Reductive stress is induced by excessive levels of reductive stressors that results from an elevation in GSH/GSSG ratio, $\mathrm{NAD}^{+} / \mathrm{NADH}, \mathrm{NADP}^{+} / \mathrm{NADPH}$ and/or or overexpression of antioxidative enzymatic systems such as the GSH system, catalase, thioredoxin-peroxiredoxin (TRX-PRDX) system, $\alpha$-ketoglutarat dehydrogenase (GPDH), and glycerol phosphate dehydrogenase $[137,138]$. The reductive stressors deplete reactive oxidative species and are harmful as oxidative stressors and implicated in pathological processes in $\mathrm{AD}, \mathrm{PD}$, and sporadic motor neuron disease, among others [139].

The GSH system consists of GSH, the enzymes for synthesis and recycling including gamma-glutamate cysteine ligase, glutathione synthetase, glutathione reductase (GSR) and gamma glutamyl transpeptidase, and the enzymes for metabolism and antioxidation including glutathione S-transferase and GPx [140]. The GPx is an enzyme containing four selenium-cofactors that catalyzes the reducion of hydrogen peroxide $\left(\mathrm{H}_{2} \mathrm{O}_{2}\right)$ to water molecule $\left(\mathrm{H}_{2} \mathrm{O}\right)$ and organic hydroperoxide (ROOH) to alcohol (ROH) by converting reduced monomeric GSH to GSSG. Glutathione s-transferases show high activity with lipid peroxides [141]. Eight isozymes are in the cytosol, membrane and plasma, protecting the organisms from oxidative stress [142].

Most studies on peripheral blood GPx activity reported nonsignificant results in a mixed population of MS [127,143-146]. However, lower mean GPx activity of erythrocyte lysates in remission and higher mean GPx were reported in acute relapse of RRMS [147]. GPx activity in CSF was found lower in MS patients [148]. The GSR activity of lymphocyte and granulocyte lysates were not significantly different in MS, compared to controls. However, a significant correlation of GPx and GRx was observed in controls, but not in MS [149]. Mean GRx activity of CSF was found significantly higher in MS patients [148] (Table 3, Table 4).

Catalases a tetrameric heme- or manganese-containing dismutase that catalyzes the conversion of two hydrogen peroxide $\left(\mathrm{H}_{2} \mathrm{O}_{2}\right)$ molecules to water $\left(\mathrm{H}_{2} \mathrm{O}\right)$ in the presence of small amount of hydrogen peroxide. The cofactor is oxidized by one molecule of hydrogen peroxide and then regenerated by transferring the bound oxygen to a second molecule of substrate. The enzyme is located in the peroxisomes, the cytosol of erythrocytes, and the mitochondria, removing harmful hydrogen peroxides to prevent cellular and tissue damage [150].

Studies on the catalase activity of peripheral blood samples reported equivocal results in MS. The catalase activity of granulocyte lysates was found lower in MS patients, compared to controls [151]. The activities of CSF and plasma catalase were found increased in CIS and RRMS patients, compared to healthy controls, and MS patients with lower EDSS had higher plasma and CSF catalase activities [152] (Table 3, Table 4).

In TRX-PRDX system PRDXs catalyze the reduction of $\mathrm{H}_{2} \mathrm{O}_{2}$ to $\mathrm{H}_{2} \mathrm{O}_{2} \mathrm{H}_{2} \mathrm{O}_{2}$ oxidizes the peroxidatic cysteine of PRDXs to protein sulfenic acid (PSOH), which can react with the thiol (SH) 
453

454

455

456

457

458

459

460

461

462

463

464

465

466

467

468

469

470

471

472

473

474

475

476

477

478

479

480

481

482

483

484

485

486

487

488

489

490

491

492

493

494

495

496 group of the resolving cysteine to yield the formation of an inter-(typical) or intramolecular (atypical) disulfide bond. TRX/TRXR system mediates the reduction of the PRDX disulfide bond. TRX reduced state is maintained by the flavoenzyme TRXR in the presence of NADPH. When $\mathrm{H}_{2} \mathrm{O}_{2}$ exceeds the normal levels, PRDXs are overoxidized from $\mathrm{PSOH}$ to protein sulfinic acids $\left(\mathrm{PSO}_{2} \mathrm{H}\right)$. The latter can be reduced back to the native form of the enzyme by sulfiredoxin (SRX) in the presence of ATP. However, further oxidation of $\mathrm{PRDX}$ s to $\mathrm{PSO}_{3} \mathrm{H}$ is irreversible [153].

Serum Trx1 was significantly increased in the newly diagnosed MS patients, compared to controls. TRX1and APEX1 mRNA expressions were significantly higher in the newly diagnosed MS patients, patients under INF- $\beta$ treatment, and patients who received immunosuppressant azathioprine or betamethasone, compared to healthy controls [154]. PRDX2 mRNA is upregulated and PRDX2 expression is higher in MS lesions white matter of autopsy tissue of patients its expression level is positively correlated with the degree of inflammation and oxidative stress [155] (Table 3, Table 4).

$\alpha$-KGDH is a mitochondrial enzyme in Krebs cycle, which catalyzes $\alpha$-ketoglutarate, coenzyme $\mathrm{A}$ and $\mathrm{NAD}^{+}$to succinyl-CoA, NADH and $\mathrm{CO}_{2}$, transferring an electron to the respiratory chain [156]. KGNH activity is sensitive to redox status. $\mathrm{H}_{2} \mathrm{O}_{2}$ reversibly inhibits $\mathrm{KGNH}$ by glutathionylation of lipoic acid cofactor, resulting reducing electron supply to the respiratory chain. A lipid peroxidation product 4-hydroxy-2-nonenal (4-HNE) reacts with lipoic acid cofactor, inhibiting $\alpha$-KGDH activity [157]. The pyruvate tolerance test showed higher activity of $\alpha$-KGDH in serum of MS patients [158]. However, reduced expression and activity of mitochondrial $\alpha$-KGDH was observed in demyelinated axons that correlated with signs of axonal dysfunction (Table 3) [159].

$\alpha-G P D H$ catalyzes the reversible redox conversion of dihydroxyacetone phosphate to sn-glycerol 3-phosphate, linking carbohydrate and lipid metabolism. A loss of $\alpha$-GPDH in oligodendrocytes were observed in chronic plaques of MS patients, suggesting the presence of antioxidant capacity impairment [160] (Table 3).

Nrf2 is a transcriptional factor of the antioxidative enzyme genes including catalase, GPx, GRx, glutathione S-transferase, and SOD. In response to oxidative stress, the Kelch-like ECH-associated protein 1 (KEAP1) inhibits the ubiquitin-proteasome system in the cytosol and facilitates the translocation of Nrf2 into the nucleus to bind to the cis-acting enhancer sequence of the promotor region, the antioxidant response elements [161,162]. Activation of the Nrf2-Keap1 pathway has been observed in various types of cancers, accompanied with reduced antioxidant capacity and elevated oxidative stress and inflammation [163]. The cytoplasmic and nucleic Nrf2 protein expression of PBMC was increased and correlated with clinical improvement in MS patients on 14-month course of natalizumab, an $\alpha 4$ integrin receptor blocker [74] (Table 3, Table 4).

Other transcriptional factors involved in energy metabolism have been investigated. Peroxisome proliferator-activated receptors (PPARs) are a transcriptional factor of the gene regulating energy metabolism including glucose metabolism, fatty acid oxidation, thermogenesis, lipid metabolism, and anti-inflammatory response [164]. PPARs have attracted growing attention as promising targets of many diseases such as diabetes and hyperlipidemia [165]. An isoform PPAR-gamma (PPAR- $\gamma$ ) was elevated in CSF samples of MS, compared to controls [166]. Peroxisome proliferator-activated receptor gamma coactivator 1- $\alpha$ (PGC-1 $\alpha) 4$ integrin receptor blocker is a transcriptional coactivator that regulates the genes involved in energy metabolism. Reduced PGC-1 $\alpha$ expression was associated with mitochondria changes and correlated with neural loss in MS [167] (Table 3, Table 4).

\subsection{Exogenous antioxidative factors}

A daily diet rich in naturally occurring polyphenolic antioxidants such as flavonoids and phenolic acids are regularly recommended for disease prevention and antioxidant supplements such as vitamin C, vitamin E, $N$-acetyl cysteine, L-carnitine and folic acid are frequently employed as a complementary therapy for various diseases $[168,169]$. Those preventive and therapeutic measures are based on the pathogenesis of diseases which are induced and developed under oxidative cellular environment. N-Methyl-D-aspartic acid receptor antagonist memantine and memantine-ferulic acid 
504

505

506

507

508

509

510

511

512

513

514

515

516

517

518

519

conjugate improved oxidative stress in patients with $\mathrm{AD}$ [170]. A meta-analysis of randomized controled trials showed that an exogenous antioxidant $N$-acetylcysteine supplement improved cognitive function in patients with schizophrenia [171]. Traditional Chinese medicine curcumin is an antioxidant and anti-imflammatory molecule that relieves pain and stress at least partly through the kynurenine metabolic pathway [172].

However, unmonitored chronic antioxidant supplementation imposes reductive stress, the counterpart of oxidative stress. The reductive stress-induced inflammation is observed in hypertrophic cardiomyopathy, muscular dystrophy, pulmonary hypertension, rheumatoid arthritis, $\mathrm{AD}$, and metabolic syndrome [139]. In adipose tissue a long-term antioxidant supplementation caused a paradoxical increase in oxidative stress which was associated with mitochondrial dysfunction [173]. Leptin secreted from adipose tissue serves as an inflammatory mediator and subsequent development of leptin resistance make obese individuals more susceptible to autoimmune disease including MS [174] (Figure 1 (c)).

Vitamin supplements are recommended for the treatment of MS, as nutritional deficits are frequently observed in patients with MS [175]. MS induced by reductive stress has not been reported, but it deserves to monitor redox status in MS patients.

\section{Degradation Products Under Oxidative Stress}

\subsection{Proteins}

Protein carbonyls are degradation products of reactions between reactive species and proteins, resulting in loss of function or aggregation. Quantification with 2,4-Dinitrophenylhydrazine products showed increased carbonylation in plasma and serum of RRMS patients [176-178]. The plasma carbonyl levels were elevated in SPMS and correlated with the EDSS, and the Beck Depression Inventory [179]. The levels of carbonyl groups were elevated in serum of patients with RRMS and lowered in the group of RRMS patients treated with INF- $\beta$ [180]. The levels of CSF carbonyl proteins measured were elevated in RRMS and progressive MS [181,182] (Table 3, Table 4).

A highly active RNS reacts with tyrosine residues of proteins to form nitrotyrosines, leading to the alternation of protein conformation function. 3-nitrotyrosine (3-NO-Tyr) is the main product of tyrosine oxidation, formed by the substitution of a hydrogen by a nitro group in the phenolic ring of the tyrosine residues. 3-NO-Tyr content is assessed by western blotting, high-performance liquid chromatography (HPLC), gas chromatography-mass spectrometry (GC/MS), and enzyme-linked immunosorbent assay (ELISA) [183]. Mean 3-NO-Tyr was observed significantly higher in plasma and serum of RRMS and SPMS patients and significantly higher 3-NO-Tyr was found in SPMS than RRMS $[177,184,185]$. Decreased mean 3-NO-Tyr was reported following relapse and corticosteroid treatment [186]. 3-NO-Tyr was found significantly lower in serum of MS patients following INF- $\beta 1 \mathrm{~b}$ treatment [187]. 3-NO-Tyr was found significantly reduced in peripheral leukocytes following GA treatment [185] (Table 3, Table 4).

Protein glutathionylation is a redox-dependent posttranslational modification that results in the formation of a mixed disulfide between GSH and the thiol group of a protein cysteine residue [188]. Protein glutathionylation is observed in response to oxidative or nitrosative stress and is redox-dependent, being readily reversible under reducing conditions. Extracellular SOD, $\alpha 1$-antitrypsin and phospholipid transfer protein were found glutathionylated at cysteine residues in CSF of MS Patients, witnessing the footprints of oxidative assault of MS [182].

Oxidative environments generate oxidized tyrosine orthologues such as o-tyrosine, m-tyrosine, nitrotyrosine, and dityrosine. Dityrosine was elevated in serum of RRMS patients [180]. Advanced oxidation protein products (AOPPs) are uremic toxins produced in reaction of plasma proteins with chlorinated oxidants such as chloramines and hypochlorous acid (HClO) [190]. The levels of AOPPs were significantly higher in plasma of MM patients [191]. The levels of AOPPs were significantly higher in plasma and CSF of CIS and RRMS patients than healthy controls, and the AOPPs levels were significantly higher CIS than RRMS. Furthermore, the levels of AOPPs were significantly 
higher in patients with higher EDSS scores than lower ones [63]. The AOPPs levels were decreased in serum of RRMS patients treated with IFN- $\beta$ [180] (Table 3, Table 4).

AGEs are a group of glycotoxins produced in reaction of free amino groups of proteins, lipids, or nucleic acids and carbonyl groups of reducing sugars. The AGEs can accumulate in tissues and body fluids, resulting in protein malfunctions, reactive chemical production, and inflammation [192]. The levels of AGEs were significantly elevated in serum of RRMS patients, but no significant change was observed after IFN- $\beta$ treatment [180]. The concentrations of AGEs were significantly higher in brain samples of MS patients, compared to nondemented counterparts. The levels of free AGEs were correlated in CSF and plasma samples of MS patients, but not protein-bound AGEs [193] (Table 3, Table 4).

\subsection{Amino Acids}

Asymmetric dimethylarginine (ADMA) is a L-arginine analogue produced in the cytoplasm in the process of protein modification. The formation of ADMA is dependent on oxidative stress status. ADMA is elevated by native or oxidized LDL and interferes with L-arginine in the production of nitric oxide (NO) [194]. Significantly higher ADMA concentrations were observed in serum and CSF of patients with RRMS and SPMS, while levels of arginine, L-homoarginine, nitrate, nitrite, ADMA did not differ between patients with MS and healthy controls [195] (Table 3, Table 4).

\subsection{Lipid Membrane and lipoproteins}

Lipids in biological membrane are major target of OS. Peroxidation of lipid membrane is initiated by ROS including superoxide anion $\left(\mathrm{O}_{2}^{-\bullet}\right)$, hydroxyl radical $\left(\mathrm{OH}^{\bullet}\right)$, hydrogen peroxide $\left(\mathrm{H}_{2} \mathrm{O}_{2}\right)$, and singlet oxygen $\left(\mathrm{O}_{2}{ }^{1} \Delta_{\mathrm{g}}\right)$ and RNS including nitric oxide radical $(\mathrm{NO} \bullet)$, peroxynitrite $\left(\mathrm{ONOO}^{-}\right)$and nitrite $\left(\mathrm{NO}_{2}{ }^{-}\right)$stealing electron from PUFAs such as arachidonic (20:4) and docosahexaenoic acid (22:6). The abstraction of bis-allylic hydrogen of PUFA leads to the formation of arachidonic acid hydroperoxyl radical ( $\left.\mathrm{ROO})^{\circ}\right)$ and hydroperoxide $(\mathrm{ROOH})$ in a chain reaction manner [45]. A portion of arachidonic acid peroxides and peroxy radicals generate endoperoxides rather than hydroperoxide $(\mathrm{ROOH})$. The endoperoxides undergoes subsequent formation of a range of bioactive intermediates such as F2-isoprostanes (F2-isoPs), MDA and 4-HNE. Hexanoyl-lysine (HEL) adduct is a lipid peroxidation by-product which is formed by the oxidation of omega-6 unsaturated fatty acid, such as linoleic acid. Hydroxyoctadecadienoic acid (HODE) is derived from the oxidation of linoleates, the most abundant PUFAs in vivo [188,189]. Meanwhile, a cyclic sugar compound inositol is a major antioxidant component of the lipid membrane, which scavenges reactive species [96].

Studies on blood F2-isoPs levels reported increases in MS, especially in RRMS and SPMS subtypes compared to controls [198,199]. A study on CSF F2-isoPs levels presented three times higher in patients with MS than ones with other neurologic diseases [200]. The levels of F2-isoPs were moderately correlated with the degree of disability, suggesting a role as a prognostic marker [201]. MDA is highly reactive aldehyde generated by the reaction between reactive species and polyunsaturated lipids to form adducts with protein or DNA [202]. Studies on blood or serum MDA reported higher levels in MS patients [80,137]. The blood MDA levels were significantly higher in RRMS than controls or CIS, higher in RRMS than in remission, and higher in remission than controls. MDA levels were elevated at relapse, while lowered at day 5 of corticosteroid treatment $[61,117]$. Studies quantifying CSF MDA consistently reported higher levels in CIS and RRMS than controls [61,148,153,203]. There are positive correlations between MDA levels of plasma and CSF, and MDA levels in plasma/CSF and EDSS [152]. The levels of 4-HNE were elevated in the CSF of PPMS, RRMS, and SPMS patients, particularly in PPMS [204]. No study regarding HEL in MS was found in literature search. The serum13-HODE was identified as a part of metabolomic signatures associated with more severe disease such as non-relapse-free MS or MS with higher EDSS [205]. The levels of 9-HODE and 13-HODE were significantly increased in CSF of CIS and RRMS patients, compared to healthy controls, but baseline levels of HODE did not differ between patients with 
602

603

604

605

606

607

608

609

610

611

612

613

614

615

616

617

618

619

signs of disease activity during up to four years of follow-up and patients without MS [206] (Table 3, Table 4).

Cholesterol oxidization products oxysterols were studied. Levels of plasma oxysterols increased in progressive MS patients and oxysterol levels were positively correlated with apolipoprotein C-II and apolipoprotein E. Furthermore, oxysterol and apolipoprotein changes were associated with conversion to SPMS [207]. Increased levels of oxidized low-density lipoprotein (oxLDL) in the serum and higher serum levels of autoantibodies against oxLDL were reported in MS patients [208,209]. Although studies on HDL levels in MS patients reported mixed results, lowered HDL antioxidant function in MS patients was observed, suggesting the involvement of lipoprotein function MS pathogenesis [208-211]. In mixed population of MS, decreased serum 24S-hydroxycholesterol and 27-hydroxycholesterol and increased CSF lathosterol, compared to healthy controls [212] (Table 3, Table 4).

\subsection{Nucleic acid}

8-Hydroxy-2'-deoxyguanosine (8-OH2dG) and 8-hydroxyguanosine (8-OHG) are biomarkers of oxidative damage of nucleic acids, which can be assessed by ELISA, as well as by direct methods such as HPLC and GC/MS [213,214]. Elevated levels of 8-OH2dG was reported in blood of RRMS patients. DNA oxidation products were proposed as diagnostic biomarkers for MS [120] (Table 3, Table 4).

\section{Conclusion and Future Perspectives}

Redox biomarkers are classified by original cellular components and enzyme mechanisms of action in redox homeostasis. Redox status can be assessed by the measurement of reactive chemical species, oxidative or antioxidative enzyme activity, and degradation products derived from proteins, amino acids, lipid membrane, and nucleic acids. Measurement of reactive chemical species and oxidative enzyme activities assesses intensity of oxidative stress, while measurement of antioxidative activity analyses compensatory capacity. Fine measurement of the various redox components may reveal diagnostic, prognostic, or predicative value to differentiate the disease status and progression (Figure 3). 


\section{Structures}

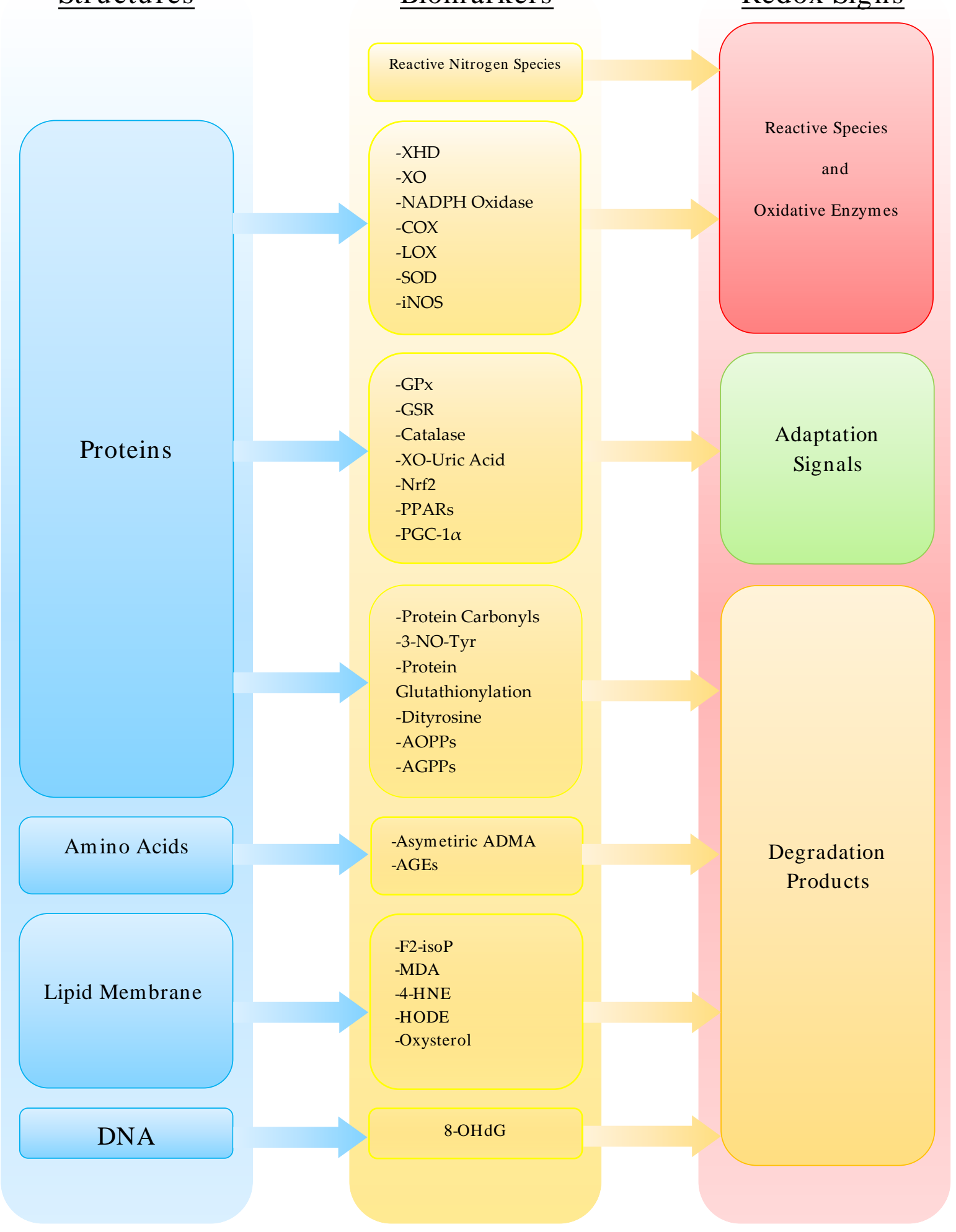

Figure 3. Classification of Redox Biomarkers According to Cellular Structures, Biomarkers, and their Modes of Action in Redox Homeostasis.

The levels of nitric oxide (NO) metabolites, S-nitrosothiol, and the activities of oxidative enzymes including SOD, MPO, and $i$ NOS have been found significantly different to patients with MS, compared to healthy controls. The levels of antioxidants including uric acid and selenium, activities of antioxidative enzymes including GSR, catalase, and TRX-PRDX, and concentrations of transcriptional factors Nrf2, PPARs, and PGC- $1 \alpha$ have been found significantly changed in MS patients. The protein degradation products including protein carbonyls, 3-NO-Tyr, 
glutathionylation, AOPPs, and AGEs, an amino acid by-product ADMA, the lipid and cholesterol degradation products including F2-isoP, MDA, 4-HNE, HODE, oxocholesterols, and oxLDL, and the nucleic acid degradation product $8-\mathrm{OH} 2 \mathrm{dG}$ significantly increased in samples of MS patients. Thus, the oxidative enzymes, antioxidative enzymes, and redox degradation products have been identified as promising biomarkers for the diagnosis of MS. Furthermore, SOD, 3-NO-Tyr, and MDA are sensitive to subtypes of MS, CIS and RRMS, RRMS and SPMS, RRMS and remission, respectively. tNOx, S-nitrosothiol, SOD, MPO, GSR, catalase, protein carbonyls, AOPPs, F2-isoP, MDA, and oxyocholesterols were correlated with EDSS and thus they are potential prognostic biomarkers for MS. SOD, Nrf2, protein carbonyls, 3-NO-Tyr, AOPPs, and MDA were observed sensitive to the treatment of MS, being possible predictive biomarkers. Finally, SOD is a possible drug target of MS as a therapeutic marker (Table 3).

In addition to biomarkers described above, search for novel biomarkers has become a growing interest in neurodegenerative diseases. A micro RNA (miRNA) is a short non-coding RNA molecule consisting of approximately 22 nucleotides, which functions in posttranscriptional gene silencing. miRNAs have been linked to pathogenesis of various diseases including cancer, autoimmune diseases, and neurodegenerative disease such as PD [215]. Dysregulated interactions of miRNAs have been reported in mild cognitive impairment and AD. The associated genes were related to regulation of ageing and mitochondria [216]. Dysregulations of various miRNAs have been observed in AD, PD, Huntington's disease, and ALS and thus miRNAs were proposed to be potential diagnostic and therapeutic biomarkers of neurodegenerative diseases [217]. The link between environmental factors and miRNA dysregulations in MS was discussed [218]. Furthermore, miRNAs in blood and CSF samples of patients with MS as diagnostic and prognostic biomarkers have been reviewed recently [219].

Long Interspersed Nuclear Element-1 (LINE-1) is an autonomous non-long terminal repeat retrotransposon that creates genomic insertions through an RNA intermediate. The increased number of germline and somatic LINE-1s have been linked to the risk and progression of cancer as well as neurodegenerative and psychiatric diseases. An increased burden of highly active retrotranposition competent LINE-1s have been associated with the risk and progression of PD and LINE-1s were proposed as possible therapeutic biomarkers that can be targeted by reverse transcriptase [220]. Furthermore, LINE-1s was considered involved in irregular immune response and participate in pathogenesis of MS [221].

A search for demographic correlation between single nucleotide polymorphisms and MS has been under extensive study. Inflammation-mediating chemokine receptor $\mathrm{V} \Delta 32$ deletion was not found correlated with MS [222]. Large-scale genome projects such as genome-wide association (GWA) studies generated polygenic risk scores for prediction of risk and progression of multifactorial neurodegenerative diseases. Large-scale pathway specific-genetic risk profiling expedited redox-related biological pathways to identify causal genes and potential therapeutic targets [223]. One of future challenges is a search for correlations with uncatalogued structural variants in MS.

Considering the dynamics of redox homeostasis, the amounts of reactive species, activities of oxidative and antioxidative enzymes, and concentrations of degradation products presumably differ during the progression of MS. The early phase presents an elevation of oxidative enzyme activity and a subsequent elevation of the activity of counteracting antioxidative enzymes with unchanged levels of degradation products. As the activity of antioxidative enzymes becomes compromised due to increasing oxidative stress, the amount of degradation products gradually increases, while the antioxidative enzyme activities slowly wane and fatigue. Eventually, the antioxidative response exhausts with elevated activities of oxidative enzymes and elevated levels of degradation products (Figure 4). Further studies and exploration into novel biomarkers are expected in search of a robust battery of biomarkers indicative to the redox status, in order to realize a fine calibration of major redox components that helps identify the disturbance of redox homeostasis, restore the nucleophilic tone and the most importantly build the best personalized treatment of MS for the sake of better quality of life [224]. 


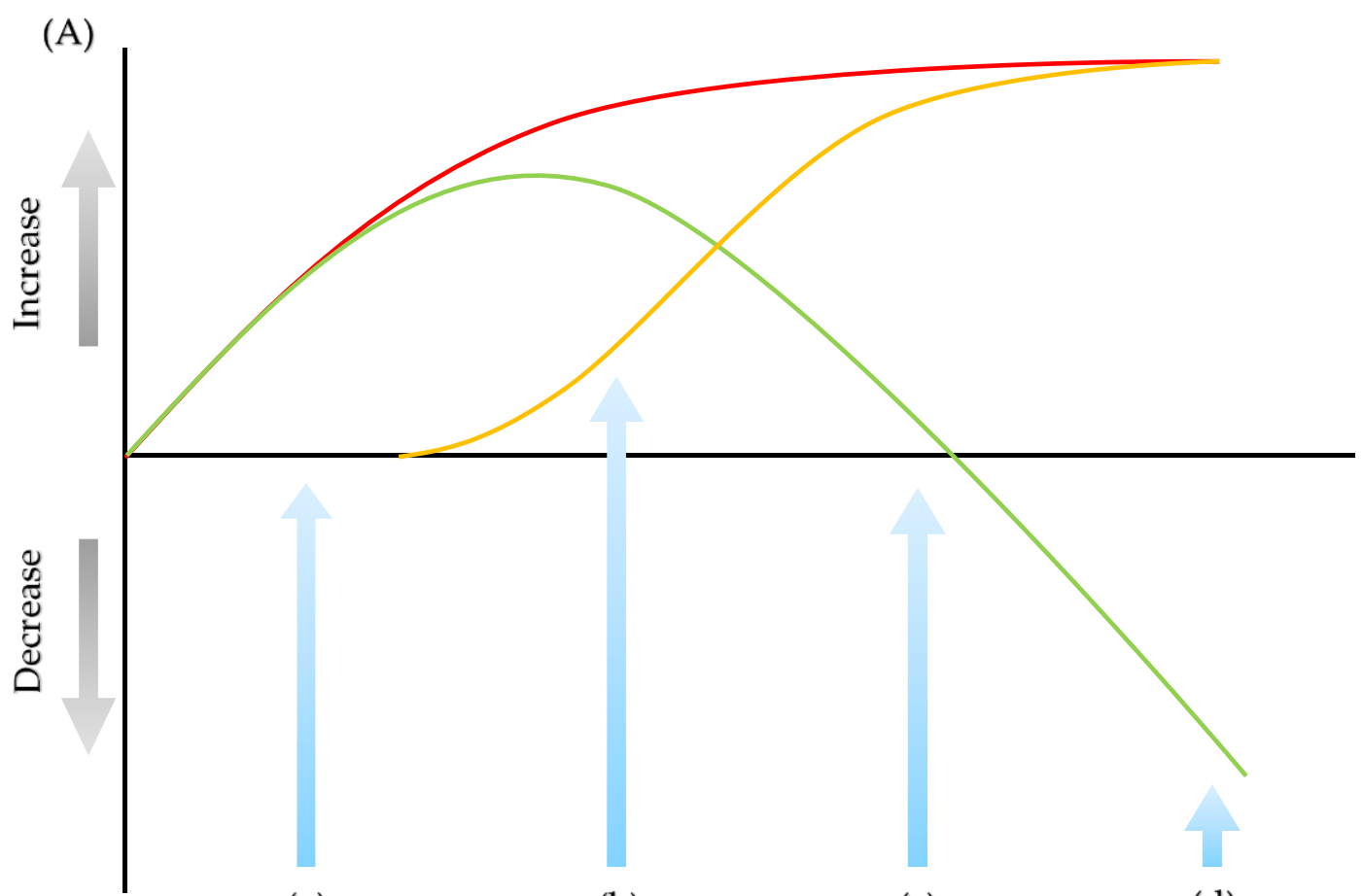

(B)

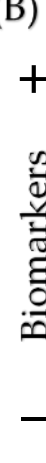

(a)

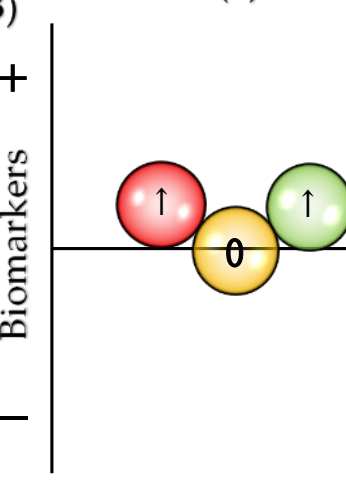

(b)

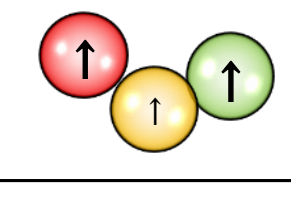

(c)

(d)

\section{Progression}

Figure 4. Dynamics of Redox Components in Disease Progression. (A) - (red line): Reactive chemical species and activities of oxidative enzymes increase gradually. - (orange line): The degradation products increase accordingly upon exhaustion of antioxidative enzymes' activities. - (green line): Antioxidative enzymes offset the effects of oxidative enzymes in the early phase, however; the antioxidative activities decline and, finally, fatigue in the later phase, resulting in the exacerbation of inflammation and cellular damage. (B) Biomarkers of three redox components may present different values. (a) The levels of oxidative enzyme slightly increase, but the degradation markers stay in a normal range. The antioxidative markers also slightly increase. (b) The oxidative markers further elevate, and the degradation markers start slightly increasing. The antioxidative markers also stay elevated. (c) The oxidative enzyme markers increase, but antioxidative markers return to normal range. The degradation product markers further elevate. (d) The oxidative markers greatly increase, but the antioxidative markers decline. The degradation products markers greatly elevate. $\bigcirc$ : oxidative biomarkers; $\bigcirc$ : degradation biomarkers; and $\bigcirc$ : antioxidative biomarkers.

Author Contributions: All authors read and agreed to the published version of the manuscript. Conceptualization, M.T. and L.V.; writing-original draft preparation, M.T.; writing - review and editing, M.T., and L.V.; visualization, M.T.; project administration, M.T.; supervision, L.V.; funding acquisition, L.V.

Funding: The current work was supported by GINOP 2.3.2-15-2016-00034, GINOP 2.3.2-15-2016-00098 (Stay Alive), TUDFO/47138-1/2019-ITM University of Szeged Open Access Fund (FundRef), Grant number 4829. 
709 Conflicts of Interest: The authors declare no conflicts of interest.

710 Abbreviations

\begin{tabular}{|c|c|}
\hline$\alpha$ & alpha \\
\hline $\mathrm{AD}$ & Alzheimer's disease \\
\hline ADMA & asymmetric dimethylarginine \\
\hline AGEs & advanced glycation end products \\
\hline ALS & amyotrophic lateral sclerosis \\
\hline AOPPs & advanced oxidation protein products \\
\hline$\beta$ & beta \\
\hline CIS & clinically isolated syndrome \\
\hline CNS & central nervous system \\
\hline $\operatorname{COX}$ & cyclooxygenase \\
\hline CSF & cerebrospinal fluid \\
\hline CYP & cytochrome P450 \\
\hline EDSS & expanded disability status scale \\
\hline ELISA & enzyme-linked immunosorbent assay \\
\hline ETC & electron transfer chain \\
\hline F2-isoPs & F2-isoprostanes \\
\hline GC/MS & gas chromatography-mass spectrometry \\
\hline $\mathrm{Gd}^{+}$ & gadolinium \\
\hline GPx & glutathione peroxidase \\
\hline GSH & glutathione \\
\hline GSSH & glutathione disulfide \\
\hline GA & glatiramer \\
\hline GPDH & ketoglutarat dehydrogenase \\
\hline GSR & glutathione reductase \\
\hline GWA & genome-wide association \\
\hline HEL & hexanoyl-lysine \\
\hline 4-HNE & 4-hydroxynonenal \\
\hline HODE & hydroxyoctadecadienoic acid \\
\hline HPLC & high-performance liquid chromatography \\
\hline$i$ NOS & inducible Nitric Oxide Synthase \\
\hline IFN & Interferon \\
\hline KEAP1 & Kelch-like ECH-associated protein 1 \\
\hline KGDH & ketoglutarate dehydrogenase \\
\hline LINE-1 & Long Interspersed Nuclear Element-1 \\
\hline LOX & lipoxygenase \\
\hline MDA & malondialdehyde \\
\hline miRNA & micro RNA \\
\hline MPO & myeloperoxidase \\
\hline MRI & magnetic resonance imaging \\
\hline MS & multiple sclerosis \\
\hline $\mathrm{NAD}^{+}$ & nicotinamide adenine dinucleotide \\
\hline $\mathrm{NADPH}$ & nicotinamide adenine dinucleotide phosphate \\
\hline NOS & nitric oxide synthetase \\
\hline 3-NO-Tyr & 3-nitrotyrosine \\
\hline NOX & nicotinamide adenine dinucleotide phosphate oxidase \\
\hline Nrf2 & nuclear factor erythroid 2-related factor \\
\hline $8-\mathrm{OH} 2 \mathrm{dG}$ & 8-Hydroxy-2'-deoxyguanosine \\
\hline 8-OHG & 8-hydroxyguanosine \\
\hline OSMS & opticospinal phenotype of relapsing-remitting multiple sclerosis \\
\hline oxLDL & oxidized low-density lipoprotein \\
\hline PD & Parkinson's disease \\
\hline PGC-1 & peroxisome proliferator-activated receptor gamma coactivator 1 \\
\hline
\end{tabular}




$\begin{array}{ll}\text { PPARs } & \text { peroxisome proliferator-activated receptors } \\ \text { PUFAs } & \text { polyunsaturated fatty acids } \\ \text { RCS } & \text { reactive carbonyl species } \\ \text { redox } & \text { reduction oxidation } \\ \text { RHS } & \text { reactive halogen species } \\ \text { RNS } & \text { reactive nitrogen species } \\ \text { ROS } & \text { reactive oxygen species } \\ \text { PPMS } & \text { primary progressive multiple sclerosis } \\ \text { PRMS } & \text { progressive-relapsing multiple sclerosis } \\ \text { RRMS } & \text { relapsing-remitting multiple sclerosis } \\ \text { RSS } & \text { reactive sulfur species } \\ \text { RSeS } & \text { reactive selenium species } \\ \text { SOD } & \text { superoxide dismutase } \\ \text { SPMS } & \text { secondary progressive multiple sclerosis } \\ \text { tNOx } & \text { total value nitric oxide } \\ \text { TRX-PRDX } & \text { thioredoxin-peroxiredoxin } \\ \text { TRXR } & \text { thioredoxin reductase } \\ \text { XDH } & \text { xanthine dehydrogenase } \\ \text { XO } & \text { xanthine oxidase }\end{array}$

\section{References}

712 1. GBD 2016 Neurology Collaborators. Global, regional, and national burden of neurological disorders, 1990-2016: a systematic analysis for the Global Burden of Disease Study 2016. Lancet Neurol. 2019, 18(5), 459-480.

2. Fricska-Nagy, Z.; Füvesi, J.; Rózsa, C.; Komoly, S.; Jakab, G.; Csépány, T.; Jobbágy, Z.; Lencsés, G.; Vécsei, L.; Bencsik, K. The effects of fatigue, depression and the level of disability on the health-related quality of life of glatiramer acetate-treated relapsing-remitting patients with multiple sclerosis in Hungary. Mult. Scler. Relat. Disord. 2016, 7, 26-32.

3. Sandi, D.; Biernacki, T.; Szekeres, D.; Füvesi, J.; Kincses, Z.T.; Rózsa, C.; Mátyás, K.; Kása, K.; Matolcsi, J.; Zboznovits, D.; Burány, Z.; Langane, É.; Vécsei, L.; Bencsik, K. Prevalence of cognitive impairment among Hungarian patients with relapsing-remitting multiple sclerosis and clinically isolated syndrome. Mult. Scler. Relat. Disord. 2017, 17, 57-62.

4. Tanaka, M.; Toldi, J.; Vécsei, L. Exploring the Etiological Links behind Neurodegenerative Diseases: Inflammatory Cytokines and Bioactive Kynurenines. Int. J. Mol. Sci. 2020, 21, 2431.

5. Boeschoten, R.E.; Braamse, A.M.J.; Beekman, A.T.F.; Cuijpers, P.; van Oppen, P.; Dekker, J.; Uitdehaag, B.M.J. Prevalence of Depression and Anxiety in Multiple Sclerosis: A Systematic Review and Meta-Analysis. J. Neurol. Sci. 2017, 372, 331-341.

6. Hunt, C.; Macedo e Cordeiro, T.; Suchting, R.; de Dios, C.; Cuellar Leal, V.A.; Soares, J.C.; Dantzer, R.; Teixeira, A.L.; Selvaraj, S. Effect of immune activation on the kynurenine pathway and depression symptoms - A systematic review and meta-analysis. Neurosci. Biobehav. Rev. 2020, 118, 514.

7. Jovanovic, F.; Candido, K.D.; Knezevic, N.N. The Role of the Kynurenine Signaling Pathway in Different Chronic Pain Conditions and Potential Use of Therapeutic Agents. Int. J. Mol. Sci. 2020, 21, 6045.

8. Waubant, E.; Lucas, R.; Mowry, E.; Graves, J.; Olsson, T.; Alfredsson, L.; Langer-Gould, A. Environmental and genetic risk factors for MS: an integrated review. Ann. Clin. Transl. Neurol. 2019, 6(9), 1905-1922.

9. Biernacki, T.; Sandi, D.; Kincses, Z.T.; Füvesi, J.; Rózsa, C.; Mátyás, K.; Vécsei, L.; Bencsik, K. Contributing factors to health-related quality of life in multiple sclerosis. Brain Behav. 2019, 9(12), e01466.

10. Rajda, C.; Majláth, Z.; Pukoli, D.; Vécsei, L. Kynurenines and Multiple Sclerosis: The Dialogue between the Immune System and the Central Nervous System. Int. J. Mol. Sci. 2015, 6, 16(8), 18270-18282.

11. Chen, Y.Y.; Wang, M.C.; Wang, Y.N.; Hu, H.H.; Liu, Q.Q.; Liu, H.J.; Zhao, Y.Y. Redox signaling and Alzheimer's disease: from pathomechanism insights to biomarker discovery and therapy strategy. Biomark. Res. 2020, 8, 42.

12. Filippi, M.; Bar-Or, A.; Piehl, F.; Preziosa, P.; Solari, A.; Vukusic, S.; Rocca, M.A. Multiple sclerosis. Nat. Rev. Dis. Primers 2018, 4(43). 
13. Kincses, Z.T.; Tóth, E.; Bankó, N.; Veréb, D.; Szabó, N.; Csete, G.; Faragó, P.; Király, A.; Bencsik, K.; Vécsei, L. Grey matter atrophy in patients suffering from multiple sclerosis. Ideggyogy Sz. 2014, 67(9-10), 293-300.

14. Tóth, E.; Faragó, P.; Király, A.; Szabó, N.; Veréb, D.; Kocsis, K.; Kincses, B.; Sandi, D.; Bencsik, K.; Vécsei, L.; Kincses, Z.T. The Contribution of Various MRI Parameters to Clinical and Cognitive Disability in Multiple Sclerosis. Front. Neurol. 2019, 9, 1172.

15. Andravizou, A.; Dardiotis, E.; Artemiadis, A.; Sokratous, M.; Siokas, V.; Tsouris, Z.; Aloizou, A,M.; Nikolaidis, I. Bakirtzis, C.; Tsivgoulis, G.; Deretzi, G.; Grigoriadis, N.; Bogdanos, D.P.; Hadjigeorgiou, G.M. Brain atrophy in multiple sclerosis: mechanisms, clinical relevance and treatment options. Autoimmun. Highlights 2019, 10(7).

16. Hartung, H.P.; Graf, J.; Aktas, O.; Mares, J.; Barnett, M.H. Diagnosis of multiple sclerosis: revisions of the McDonald criteria 2017 - continuity and change. Curr. Opin. Neurol. 2019, 32(3), 327-337.

17. Iacobaeus, E.; Arrambide, G.; Pia Amato, M.; Derfuss, T.; Vukusic, S.; Hemmer, B.; Tintore, M.; Brundin, L.; 2018 ECTRIMS Focused Workshop Group. Aggressive multiple sclerosis (1): Towards a definition of the phenotype. Mult. Scler. 2020, 1352458520925369.

18. Correale, J.; Marrodan, M.; Ysrraelit, M.C. Mechanisms of Neurodegeneration and Axonal Dysfunction in Progressive Multiple Sclerosis. Biomedicines 2019, 7(1), 14.

19. Melendez-Torres, G.J.; Armoiry, X.; Court, R.; Patterson, J.; Kan, A.; Auguste, P.; Madan, J.; Counsell, Carl.; Ciccarelli, O.; Clarke, A. Comparative effectiveness of beta-interferons and glatiramer acetate for relapsing-remitting multiple sclerosis: systematic review and network meta-analysis of trials including recommended dosages. BMC Neurol. 2018, 18(1), 162.

20. Goodman, A.D.; Anadani, N.; Gerwitz, L. Siponimod in the treatment of multiple sclerosis. Expert Opin. Investig. Drugs 2019, 28(12), 1051-1057.

21. Robertson, D; Moreo, N. Disease-Modifying Therapies in Multiple Sclerosis: Overview and Treatment Considerations. Fed Pract. 2016, 33(6), 28-34.

22. Jonasson, E.; Sejbaek, T. Diroximel fumarate in the treatment of multiple sclerosis. Neurodegener. Dis. Manag. 2020 Jul 20. doi: 10.2217/nmt-2020-0025. Epub ahead of print. PMID: 32686599.

23. Hauser SL, Bar-Or A, Cohen JA, Comi G, Correale J, Coyle PK, Cross AH, de Seze J, Leppert D, Montalban X, Selmaj K, Wiendl H, Kerloeguen C, Willi R, Li B, Kakarieka A, Tomic D, Goodyear A, Pingili R, Häring DA, Ramanathan K, Merschhemke M, Kappos L; ASCLEPIOS I and ASCLEPIOS II Trial Groups. Ofatumumab versus Teriflunomide in Multiple Sclerosis. N Engl J Med. 2020 Aug 6;383(6):546-557.

24. Hojati, Z; Kay, M.; Dehghanian, F. Mechanism of Action of Interferon Beta in Treatment of Multiple Sclerosis. In Multiple Sclerosis, A Mechanistic View, 1st ed.; Minagar, A., Ed.; Academic Press: 2016; pp. 365-392.

25. Ziemssen T, Schrempf W. Glatiramer acetate: mechanisms of action in multiple sclerosis. Int. Rev. Neurobiol. 2007, 79, 537-570.

26. De Angelis, F.; John, N.A.; Brownlee, W.J. Disease-modifying therapies for multiple sclerosis. BMJ. 2018, 363, k4674.

27. Rajda, C.; Bergquist, J.; Vécsei L. Kynurenines, redox disturbances and neurodegeneration in multiple sclerosis. J. Neural. Transm. Suppl. 2007, (72), 323-329.

28. Rajda, C.; Pukoli, D.; Bende, Z.; Majláth, Z.; Vécsei L. Excitotoxins, Mitochondrial and Redox Disturbances in Multiple Sclerosis. Int. J. Mol. Sci. 2017, 18(2), 353.

29. Sas, K.; Szabó, E.; Vécsei, L. Mitochondria, Oxidative Stress and the Kynurenine System, with a Focus on Ageing and Neuroprotection. Molecules 2018, 23(1), 191.

30. Fiorini, A.; Koudriavtseva, T.; Bucaj, E.; Coccia, R.; Foppoli, C.; Giorgi, A.; Schininà, M.E.; Di Domenico, F.; De Marco, F.; Perluigi, M. Involvement of oxidative stress in occurrence of relapses in multiple sclerosis: the spectrum of oxidatively modified serum proteins detected by proteomics and redox proteomics analysis. PLoS One 2013, 8(6), e65184.

31. Choi, I.Y.; Lee, P.; Adany, P.; Hughes, A.J.; Belliston, S.; Denney, D.R.; Lynch, S.G. In vivo evidence of oxidative stress in brains of patients with progressive multiple sclerosis. Mult. Scler. 2018, 24(8), 1029-1038.

32. Barcelos, I.P.; Troxell, R.M.; Graves, J.S. Mitochondrial Dysfunction and Multiple Sclerosis. Biology 2019, 8, 37.

33. Cortese-Krott, M.M.; Koning, A.; Kuhnle, G.G.C.; Nagy, P.; Bianco, C.L.; Pasch, A.; Wink, D.A.; Fukuto, J.M.; Jackson, A.A.; van Goor, H.; Olson, K.R.; Feelisch, M. The Reactive Species Interactome: Evolutionary 
Emergence, Biological Significance, and Opportunities for Redox Metabolomics and Personalized Medicine. Antioxid. Redox Signal 2017, 27(10), 684-712.

34. Santolini, J.; Wootton, S.A.; Jackson, A.A.; Feelisch, M. The Redox architecture of physiological function. Curr. Opin. Physiol. 2019, 9, 34-47.

35. Sies, H. On the history of oxidative stress: Concept and some aspects of current development. Curr. Opin. Toxicol. 2018, 7, 122-126.

36. Viña, J; Lloret, A.; Vallés, SL.; Borrás, C.; Badía, MC.; Pallardó, F.V.; Sastre, J.; Alonso, M.D. Mitochondrial oxidant signalling in Alzheimer's disease. J. Alzheimers Dis. 2007, 11(2), 175-181.

37. Pizzino, G.; Irrera, N.; Cucinotta, M.; Pallio, G.; Mannino, F.; Arcoraci, V.; Squadrito, F.; Altavilla, D.; Bitto, A. Oxidative Stress: Harms and Benefits for Human Health. Oxid. Med. Cell Longev. 2017, 2017, 8416763.

38. Török, N.; Majláth, Z.; Fülöp, F.; Toldi, J.; Vécsei, L. Brain Aging and Disorders of the Central Nervous System: Kynurenines and Drug Metabolism. Curr. Drug Metab. 2016, 17(5), 412-429.

39. Frijhoff, J.; Winyard, P.G.; Zarkovic, N.; Davies, S.S.; Stocker, R.; Cheng, D.; Knight, A.R.; Taylor, E.L.; Oettrich, J.; Ruskovska, T.; Gasparovic, A.C.; Cuadrado, A.; Weber, D.; Poulsen, H.E.; Grune, T.; Schmidt, H.H.; Ghezzi, P. Clinical Relevance of Biomarkers of Oxidative Stress. Antioxid. Redox Signal 2015, 23(14), 1144-1170.

40. Tanaka, M.; Bohár, Z.; Vécsei, L. Are Kynurenines Accomplices or Principal Villains in Dementia? Maintenance of Kynurenine Metabolism. Molecules 2020, 25, 564.

41. Bhattacharyya, A.; Chattopadhyay, R.; Mitra, S.; Crowe S.E. Oxidative Stress: An Essential Factor in the Pathogenesis of Gastrointestinal Mucosal Diseases. Physiol. Rev. 2014, 94(2), 329-354.

42. Aguilera, G, Colín-González, A.L.; Rangel-López, E.; Chavarría, A.; Santamaría, A. Redox Signaling, Neuroinflammation, and Neurodegeneration. Antioxid. Redox Signal. 2018, 28(18), 1626-1651.

43. Lushchak, V.I. Free radicals, reactive oxygen species, oxidative stress and its classification. Chem. Biol. Interact. 2014, 224, 164-175.

44. Di Meo, S.; Reed, T.T.; Venditti, P.; Victor, V.M. Role of ROS and RNS Sources in Physiological and Pathological Conditions. Oxid. Med. Cell Longev. 2016, 2016, 1245049.

45. Collin, F. Chemical Basis of Reactive Oxygen Species Reactivity and Involvement in Neurodegenerative Diseases. Int. J. Mol. Sci. 2019, 20, 2407.

46. Drulovic. J.; Dujmovic, I.; Stojsavljevic, N.; Mesaros, S.; Andjelkovic, S.; Miljkovic, D.; Peric, V.; Dragutinovic, G.; Marinkovic, J.; Levic, Z.; Mostarica Stojkovic, M. Uric acid levels in sera from patients with multiple sclerosis. J. Neurol. 2001, 248(2), 121-126.

47. Prasad, A.; Balukova, A.; Pospíšil, P. Triplet Excited Carbonyls and Singlet Oxygen Formation During Oxidative Radical Reaction in Skin. Front. Physiol. 2018, 9, 1109.

48. Nordzieke, D.E.; Medraño-Fernandez, I. The Plasma Membrane: A Platform for Intra- and Intercellular Redox Signaling. Antioxidants 2018, 7, 168.

49. Doğan, H.O.; Yildiz, Ö.K. Serum NADPH oxidase concentrations and the associations with iron metabolism in relapsing remitting multiple sclerosis. J. Trace Elem. Med. Biol. 2019, 55, 39-43.

50. Yahfoufi, N.; Alsadi, N.; Jambi, M.; Matar, C. The Immunomodulatory and Anti-Inflammatory Role of Polyphenols. Nutrients 2018, 10, 1618.

51. Azadmanesh, J.; Borgstahl, G.E.O. A Review of the Catalytic Mechanism of Human Manganese Superoxide Dismutase. Antioxidants 2018, 7, 25.

52. Pospíšil, P.; Prasad, A.; Rác, M. Mechanism of the Formation of Electronically Excited Species by Oxidative Metabolic Processes: Role of Reactive Oxygen Species. Biomolecules 2019, 9, 258.

53. Di Marzo, N.; Chisci, E.; Giovannoni, R. The Role of Hydrogen Peroxide in Redox-Dependent Signaling: Homeostatic and Pathological Responses in Mammalian Cells. Cells 2018, 7, 156.

54. Case, A.J. On the Origin of Superoxide Dismutase: An Evolutionary Perspective of Superoxide-Mediated Redox Signaling. Antioxidants 2017, 6, 82.

55. Azadmanesh, J.; Borgstahl, G.E.O. A Review of the Catalytic Mechanism of Human Manganese Superoxide Dismutase. Antioxidants 2018, 7, 25.

56. Weidinger, A.; Kozlov, A.V. Biological Activities of Reactive Oxygen and Nitrogen Species: Oxidative Stress versus Signal Transduction. Biomolecules 2015, 5, 472-484.

57. Ježek, J.; Cooper, K.F.; Strich, R. Reactive Oxygen Species and Mitochondrial Dynamics: The Yin and Yang of Mitochondrial Dysfunction and Cancer Progression. Antioxidants 2018, 7, 13. 
58. Klivenyi, P.; Karg, E.; Rozsa, C.; Horvath, R.; Komoly, S.; Nemeth, I.; Turi, S.; Vecsei, L. alpha-Tocopherol/lipid ratio in blood is decreased in patients with Leber's hereditary optic neuropathy and asymptomatic carriers of the 11778 mtDNA mutation. J. Neurol. Neurosurg. Psychiatry 2001, 70(3), 359-362.

59. Ahmad, W.; Ijaz, B.; Shabbiri, K.; Ahmed, F.; Rehman, S. Oxidative toxicity in diabetes and Alzheimer's disease: mechanisms behind ROS/ RNS generation. J. Biomed. Sci., 2017, 24(1), 76.

60. Ljubisavljevic, S.; Stojanovic, I.; Cvetkovic, T.; Vojinovic, S.; Stojanov, D.; Stojanovic, D.; Stefanovic, N.; Pavlovic, D. Erythrocytes' antioxidative capacity as a potential marker of oxidative stress intensity in neuroinflammation. J. Neurol. Sci. 2014, 337(1-2), 8-13.

61. Mitosek-Szewczyk, K.; Gordon-Krajcer, W.; Walendzik, P.; Stelmasiak, Z. Free radical peroxidation products in cerebrospinal fluid and serum of patients with multiple sclerosis after glucocorticoid therapy. Folia Neuropathol, 2010, 48(2), 116-122.

62. Inarrea, P.; Alarcia, R.; Alava, M.A.; Capablo, J.L.; Casanova, A.; Iñiguez, C.; Iturralde, M.; Larrodé, P.; Martín, J.; Mostacero, E.; Ara, J.R. Mitochondrial complex enzyme activities and cytochrome C expression changes in multiple sclerosis. Mol. Neurobiol. 2014, 49(1), 1-9.

63. Ljubisavljevic, S.; Stojanovic, I.; Vojinovic, S.; Stojanov, D.; Stojanovic, S.; Cvetkovic, T.; Savic, D.; Pavlovic, $\mathrm{D}$. The patients with clinically isolated syndrome and relapsing remitting multiple sclerosis show different levels of advanced protein oxidation products and total thiol content in plasma and CSF. Neurochem. Int. 2013, 62(7), 988-997.

64. Damiano, S.; Sasso, A.; De Felice, B.; Terrazzano, G.; Bresciamorra, V.; Carotenuto, A.; Orefice, N.S.; Orefice, G.; Vacca, G.; Belfiore, A.; Santillo, M.; Mondola, P. The IFN-beta $1 \mathrm{~b}$ effect on Cu Zn superoxide dismutase (SOD1) in peripheral mononuclear blood cells of relapsing-remitting multiple sclerosis patients and in neuroblastoma SK-N-BE cells. Brain Res. Bull. 2015, 118, 1-6.

65. Tasset, I.; Bahamonde, C.; Agüera,; E, Conde, C.; Cruz, A.H.; Pérez-Herrera, A.; Gascón, F.; Giraldo, A.I.; Ruiz, M.C.; Lillo, R.; Sánchez-López, F.; Túnez, I. Effect of natalizumab on oxidative damage biomarkers in relapsing-remitting multiple sclerosis. Pharmacol. Rep. 2013, 65(3), 624-631.

66. Spinello, A.; Ritacco, I.; Magistrato, A. The Catalytic Mechanism of Steroidogenic Cytochromes P450 from All-Atom Simulations: Entwinement with Membrane Environment, Redox Partners, and Post-Transcriptional Regulation. Catalysts 2019, 9, 81.

67. Irazabal, M.V.; Torres, V.E. Reactive Oxygen Species and Redox Signaling in Chronic Kidney Disease. Cells 2020, 9, 1342.

68. Onukwufor, J.O.; Berry, B.J.; Wojtovich, A.P. Physiologic Implications of Reactive Oxygen Species Production by Mitochondrial Complex I Reverse Electron Transport. Antioxidants 2019, 8, 285.

69. Aggarwal, V.; Tuli, H.S.; Varol, A.; Thakral, F.; Yerer, M.B.; Sak, K.; Varol, M.; Jain, A.; Khan, M.A.; Sethi, G. Role of Reactive Oxygen Species in Cancer Progression: Molecular Mechanisms and Recent Advancements. Biomolecules 2019, 9, 735.

70. Siendones, E.; Ballesteros, M.; Navas, P. Cellular and Molecular Mechanisms of Recessive Hereditary Methaemoglobinaemia Type II. J. Clin. Med. 2018, 7, 341.

71. Lismont, C.; Revenco, I.; Fransen, M. Peroxisomal Hydrogen Peroxide Metabolism and Signaling in Health and Disease. Int. J. Mol. Sci. 2019, 20, 3673.

72. Chu, R.; Lin, Y.; Reddy, K.C.; Pan, J.; Rao, M.S.; Reddy, J.K.; Yeldandi, A.V. Transformation of epithelial cells stably transfected with $\mathrm{H}_{2} \mathrm{O}_{2}$-generating peroxisomal urate oxidase. Cancer Res. 1996, 56, 4846-4852.

73. Gray, E.; Rice, C.; Hares, K.; Redondo, J.; Kemp, K.; Williams, M.; Brown, A.; Scolding, N.; Wilkins A. Reductions in neuronal peroxisomes in multiple sclerosis grey matter. Mult. Scler. 2014, 20(6), 651-659.

74. Lin, K.-J.; Lin, K.-L.; Chen, S.-D.; Liou, C.-W.; Chuang, Y.-C.; Lin, H.-Y.; Lin, T.-K. The Overcrowded Crossroads: Mitochondria, Alpha-Synuclein, and the Endo-Lysosomal System Interaction in Parkinson's Disease. Int. J. Mol. Sci. 2019, 20, 5312.

75. Chobot, V.; Hadacek, F.; Kubicova, L. Effects of Selected Dietary Secondary Metabolites on Reactive Oxygen Species Production Caused by Iron(II) Autoxidation. Molecules 2014, 19, 20023-20033.

76. Onyango, A.N. Endogenous Generation of Singlet Oxygen and Ozone in Human and Animal Tissues: Mechanisms, Biological Significance, and Influence of Dietary Components. Oxid. Med. Cell Longev. 2016, 2016, 2398573.

77. Adams, L.; Franco, M.C.; Estevez, A.G. Reactive nitrogen species in cellular signaling. Exp Biol Med (Maywood) 2015, 240(6), 711-717. 
78. Marrocco, I.; Altieri, F.; Peluso, I. Measurement and Clinical Significance of Biomarkers of Oxidative Stress in Humans. Oxid. Med. Cell Longev. 2017, 2017, 6501046.

79. Nasyrova, R.F.; Moskaleva, P.V.; Vaiman, E.E.; Shnayder, N.A.; Blatt, N.L.; Rizvanov, A.A. Genetic Factors of Nitric Oxide's System in Psychoneurologic Disorders. Int. J. Mol. Sci. 2020, 21, 1604.

80. Tavazzi, B.; Batocchi, A.P.; Amorini, A.M.; Nociti, V.; D'Urso, S.; Longo, S.; Gullotta, S.; Picardi, M.; Lazzarino G. Serum Metabolic Profile in Multiple Sclerosis Patients. Mult. Scler. Int. 2011, 2011, 167156.

81. Rejdak, K.; Petzold, A.; Stelmasiak, Z.; Giovannoni, G. Cerebrospinal fluid brain specific proteins in relation to nitric oxide metabolites during relapse of multiple sclerosis. Mult. Scler. 2008, 14(1), 59-66.

82. Giovannoni, G.; Miller, D.H.; Losseff, N.A.; Sailer, M.; Lewellyn-Smith, N.; Thompson, A.J.; Thompson, E.J. Serum inflammatory markers and clinical/MRI markers of disease progression in multiple sclerosis. J. Neurol. 2001, 248(6), 487-495.

83. Peltola, J.; Ukkonen, M.; Moilanen, E.; Elovaara, I. Increased nitric oxide products in CSF in primary progressive MS may reflect brain atrophy. Neurology 2001, 57(5), 895-896.

84. Acar, G.; Idiman, F.; Idiman, E.; Kirkali, G.; Cakmakci, H.; Ozakbas, S. Nitric oxide as an activity marker in multiple sclerosis. J. Neurol. 2003, 250(5), 588-592.

85. Danilov, A.I.; Andersson, M.; Bavand, N.; Wiklund, N.P.; Olsson, T.; Brundin, L. Nitric oxide metabolite determinations reveal continuous inflammation in multiple sclerosis. J. Neuroimmunol. 2003, 136(1-2), 112-118.

86. Svenningsson, A.; Petersson, A.S.; Andersen, O.; Hansson, GK. Nitric oxide metabolites in CSF of patients with MS are related to clinical disease course. Neurology 1999, 53(8), 1880-1882.

87. Brundin, L.; Morcos, E.; Olsson, T.; Wiklund, N.P.; Andersson, M. Increased intrathecal nitric oxide formation in multiple sclerosis; cerebrospinal fluid nitrite as activity marker. Eur. J. Neurol. 1999, 6(5), 585-590.

88. Xue, Q.; Yan, Y.; Zhang, R.; Xiong, H. Regulation of iNOS on Immune Cells and Its Role in Diseases. Int. J. Mol. Sci. 2018, 19, 3805.

89. Fernando, V.; Zheng, X.; Walia, Y.; Sharma, V.; Letson, J.; Furuta, S. S-Nitrosylation: An Emerging Paradigm of Redox Signaling. Antioxidants 2019, 8, 404.

90. Pérez-Torres, I.; Manzano-Pech, L.; Rubio-Ruíz, M.E.; Soto, M.E.; Guarner-Lans, V. Nitrosative Stress and Its Association with Cardiometabolic Disorders. Molecules 2020, 25, 2555.

91. Bryll, A.; Skrzypek, J.; Krzyściak, W.; Szelągowska, M.; Śmierciak, N.; Kozicz, T.; Popiela, T. Oxidative-Antioxidant Imbalance and Impaired Glucose Metabolism in Schizophrenia. Biomolecules 2020, 10, 384.

92. Zhang, X.; Zhang, D.; Sun, W.; Wang, T. The Adaptive Mechanism of Plants to Iron Deficiency via Iron Uptake, Transport, and Homeostasis. Int. J. Mol. Sci. 2019, 20, 2424.

93. Venditti, P.; Di Meo, S. The Role of Reactive Oxygen Species in the Life Cycle of the Mitochondrion. Int. J. Mol. Sci. 2020, 21, 2173.

94. López-Gambero, A.J.; Sanjuan, C.; Serrano-Castro, P.J.; Suárez, J.; Rodríguez de Fonseca, F. The Biomedical Uses of Inositols: A Nutraceutical Approach to Metabolic Dysfunction in Aging and Neurodegenerative Diseases. Biomedicines 2020, 8, 295.

95. Gliozzi, M.; Scicchitano, M.; Bosco, F.; Musolino, V.; Carresi, C.; Scarano, F.; Maiuolo, J.; Nucera, S.; Maretta, A.; Paone, S.; Mollace, R.; Ruga, S.; Zito, M.C.; Macrì, R.; Oppedisano, F.; Palma, E.; Salvemini, D.; Muscoli, C.; Mollace, V. Modulation of Nitric Oxide Synthases by Oxidized LDLs: Role in Vascular Inflammation and Atherosclerosis Development. Int. J. Mol. Sci. 2019, 20, 3294.

96. Lopez-Moratalla, N; Gonzalez, A.; Aymerich, M.S.; López-Zabalza, M.J.; Pío, R.; de Castro, P.; Santiago E. Monocyte inducible nitric oxide synthase in multiple sclerosis: regulatory role of nitric oxide. Nitric Oxide 1997, 1(1), 95-104.

97. Calabrese, V.; Scapagnini, G.; Ravagna, A.; Bella, R.; Foresti, R.; Bates, T.E.; Giuffrida Stella, A.M.; Pennisi, G. Nitric oxide synthase is present in the cerebrospinal fluid of patients with active multiple sclerosis and is associated with increases in cerebrospinal fluid protein nitrotyrosine and S-nitrosothiols and with changes in glutathione levels. J. Neurosci. Res. 2002, 70(4), 580-587.

98. Giles, G.I.; Nasim, M.J.; Ali, W.; Jacob, C. The Reactive Sulfur Species Concept: 15 Years On. Antioxidants 2017, 6, 38.

99. Schöneich, C. Thiyl Radical Reactions in the Chemical Degradation of Pharmaceutical Proteins. Molecules $2019,24,4357$. 
100. Ramírez, R.E.; García-Martínez, C.; Méndez, F. Understanding the Nucleophilic Character and Stability of the Carbanions and Alkoxides of 1-(9-Anthryl)ethanol and Derivatives. Molecules 2013, 18, 10254-10265.

101. Bjørklund, G.; Crisponi, G.; Nurchi, V.M.; Cappai, R.; Buha Djordjevic, A.; Aaseth, J. A Review on Coordination Properties of Thiol-Containing Chelating Agents Towards Mercury, Cadmium, and Lead. Molecules 2019, 24, 3247.

102. Głowacka, U.; Brzozowski, T.; Magierowski, M. Synergisms, Discrepancies and Interactions between Hydrogen Sulfide and Carbon Monoxide in the Gastrointestinal and Digestive System Physiology, Pathophysiology and Pharmacology. Biomolecules 2020, 10, 445.

103. Benchoam, D.; Cuevasanta, E.; Möller, M.N.; Alvarez, B. Hydrogen Sulfide and Persulfides Oxidation by Biologically Relevant Oxidizing Species. Antioxidants 2019, 8, 48.

104. McBean, G.J. Cysteine, Glutathione, and Thiol Redox Balance in Astrocytes. Antioxidants 2017, 6, 62.

105. Marozkina, N.; Gaston, B. An Update on Thiol Signaling: S-Nitrosothiols, Hydrogen Sulfide and a Putative Role for Thionitrous Acid. Antioxidants 2020, 9, 225.

106. McNeil, N.M.R.; McDonnell, C.; Hambrook, M.; Back, T.G. Oxidation of Disulfides to Thiolsulfinates with Hydrogen Peroxide and a Cyclic Seleninate Ester Catalyst. Molecules 2015, 20, 10748-10762.

107. Grman, M.; Nasim, M.J.; Leontiev, R.; Misak, A.; Jakusova, V.; Ondrias, K.; Jacob, C. Inorganic Reactive Sulfur-Nitrogen Species: Intricate Release Mechanisms or Cacophony in Yellow, Blue and Red? Antioxidants 2017, 6, 14.

108. Nagahara, N.; Wróbel, M. H2S, Polysulfides, and Enzymes: Physiological and Pathological Aspects. Biomolecules 2020, 10, 640.

109. Kolluru, G.K.; Shen, X.; Kevil, C.G. Reactive Sulfur Species: A New Redox Player in Cardiovascular Pathophysiology. Arterioscler. Thromb. Vasc. Biol. 2020, 40(4), 874-884.

110. Bild, W.; Ciobica, A.; Padurariu, M.; Bild, V. The interdependence of the reactive species of oxygen, nitrogen, and carbon. J. Physiol. Biochem. 2013, 69(1), 147-154.

111. Monti, D A.; Zabrecky, G.; Leist, T.P.; Wintering, N.; Bazzan, A.J.; Zhan, T. Newberg, A.B. N-acetyl Cysteine Administration Is Associated With Increased Cerebral Glucose Metabolism in Patients With Multiple Sclerosis: An Exploratory Study. Front. Neurol. 2020, 11, 88.

112. Krysko, K.; Bischof, A.; Nourbakhsh, B.; Henry, R.; Revirajan, N.; Manguinao, M.; Li, Y.; Waubant, E. $\mathrm{N}$-acetyl cysteine for fatigue in progressive multiple sclerosis: A pilot randomized double-blind placebo-controlled trial (P5.2-093). Neurology 2019, 92 (15 Supplement).

113. Singhal, N.K.; Freeman, E.; Arning, E.; Wasek, B.; Clements, R.; Sheppard, C.; Blake, P. Bottiglieri, T.; McDonough, J. Dysregulation of methionine metabolism in multiple sclerosis. Neurochem. Int. 2018, 112, $1-4$.

114. Mir F, et al "Methionine metabolism is altered in multiple sclerosis" SfN 2017; Abstract 475.16/N2; (Available online: https://www.medpagetoday.com/meetingcoverage/sfn/69274. 24 June 2020).

115. Roy, D; Chen, J.; Mamane, V. Methionine Metabolism Shapes T Helper Cell Responses through Regulation of Epigenetic Reprogramming. Cell Metabolism 2020, 31(2), 250-266.

116. Ferreira, B.; Mendes, F.; Osório, N.; Caseiro, A.; Gabriel, A.; Valado, A. Glutathione in multiple sclerosis. Br. J. Biomed. Sci. 2013, 70(2), 75-79.

117. Karg, E.; Klivényi, P.; Németh, I.; Bencsik, K.; Pintér, S.; Vécsei L. Nonenzymatic antioxidants of blood in multiple sclerosis. J. Neurol. 1999, 246(7), 533-539.

118. Fominykh, V.; Onufriev, M.V.; Vorobyeva, A.; Brylev, L.; Yakovlev, A.A.; Zakharova, M.N.; Gulyaeva, N.V. Increased S-nitrosothiols are associated with spinal cord injury in multiple sclerosis. J. Clin. Neurosci. 2016, 28, 38-42.

119. Antognelli, C.; Perrelli, A.; Armeni, T.; Nicola Talesa, V.; Retta, S.F. Dicarbonyl Stress and S-Glutathionylation in Cerebrovascular Diseases: A Focus on Cerebral Cavernous Malformations. Antioxidants 2020, 9, 124.

120. Hwang, S.W.; Lee, Y.-M.; Aldini, G.; Yeum, K.-J. Targeting Reactive Carbonyl Species with Natural Sequestering Agents. Molecules 2016, 21, 280.

121. Pérez-Pérez, A.; Sánchez-Jiménez, F.; Vilariño-García, T.; Sánchez-Margalet, V. Role of Leptin in Inflammation and Vice Versa. Int. J. Mol. Sci. 2020, 21, 5887.

122. Khan, A.A.; Alsahli, M.A.; Rahmani, A.H. Myeloperoxidase as an Active Disease Biomarker: Recent Biochemical and Pathological Perspectives. Med. Sci. 2018, 6, 33. 
1012

1013

1014

1015

1016

1017

1018

1019

1020

1021

1022

1023

1024

1025

1026

1027

1028

1029

1030

1031

1032

1033

1034

1035

1036

1037

1038

1039

1040

1041

1042

1043

1044

1045

1046

1047

1048

1049

1050

1051

1052

1053

1054

1055

1056

1057

1058

1059

1060

1061

1062

1063

1064
123. Mannino, M.H.; Patel, R.S.; Eccardt, A.M.; Janowiak, B.E.; Wood, D.C.; He, F.; Fisher, J.S. Reversible Oxidative Modifications in Myoglobin and Functional Implications. Antioxidants 2020, 9, 549.

124. Gonos, E.S.; Kapetanou, M.; Sereikaite, J.; Bartosz, G.; Naparło, K.; Grzesik, M.; Sadowska-Bartosz, I. Origin and pathophysiology of protein carbonylation, nitration and chlorination in age-related brain diseases and aging. Aging (Albany NY) 2018, 10(5), 868-901.

125. Mostert, J.P.; Ramsaransing, G.S.; Heersema, D.J.; Heerings, M.; Wilczak, N.; De Keyser, J. Serum uric acid levels and leukocyte nitric oxide production in multiple sclerosis patients outside relapses. J. Neurol. Sci. 2005, 231(1-2), 41-44.

126. Minohara, M.; Matsuoka, T.; Li, W.; Osoegawa, M.; Ishizu, T.; Ohyagi, Y.; Kira, J. Upregulation of myeloperoxidase in patients with opticospinal multiple sclerosis: positive correlation with disease severity. J. Neuroimmunol. 2006, 178(1-2), 156-160.

127. Tasset, I.; Aguera, E.; Sanchez-Lopez, F.; Feijóo, M.; Giraldo, A.I.; Cruz, A.H.; Gascón, Félix.; Túnez, I. Peripheral oxidative stress in relapsing remitting multiple sclerosis. Clin. Biochem. 2012, 45(6), 440-444.

128. Cupp-Sutton, K.A.; Ashby, M.T. Biological Chemistry of Hydrogen Selenide. Antioxidants 2016, 5, 42.

129. Misra, S.; Boylan, M.; Selvam, A.; Spallholz, J.E.; Björnstedt, M. Redox-Active Selenium Compounds-From Toxicity and Cell Death to Cancer Treatment. Nutrients 2015, 7, 3536-3556.

130. Zoidis, E.; Seremelis, I.; Kontopoulos, N.; Danezis, G.P. Selenium-Dependent Antioxidant Enzymes: Actions and Properties of Selenoproteins. Antioxidants 2018, 7, 66.

131. Socha, K.; Kochanowicz, J.; Karpińska, E.; Soroczyńska, J.; Jakoniuk, M.; Mariak, Z.; Borawska, M.H. Dietary habits and selenium, glutathione peroxidase and total antioxidant status in the serum of patients with relapsing-remitting multiple sclerosis. Nutr. J. 2014, 13, 62.

132. Grandi, C.; D'Ovidio, M.C. Balance between Health Risks and Benefits for Outdoor Workers Exposed to Solar Radiation: An Overview on the Role of Near Infrared Radiation Alone and in Combination with Other Solar Spectral Bands. Int. J. Environ. Res. Public Health 2020, 17(4), 1357.

133. Karimi, A.; Bahrampour, K.; Momeni Moghaddam, M.A.; Asadikaram, G.; Ebrahimi, G.; Torkzadeh-Mahani, M.; Esmaeili Tarzi, M.; Nematollahi, M.H. Evaluation of lithium serum level in multiple sclerosis patients: A neuroprotective element. Mult. Scler. Relat. Disord. 2017, 17, 244-248.

134. Juybari, K.B.; Ebrahimi, G.; Momeni Moghaddam, M.A.; Asadikaram, G.; Torkzadeh-Mahani, M.; Akbari, M.; Mirzamohammadi, S.; Karimi, A.; Nematollahi, M.H. Evaluation of serum arsenic and its effects on antioxidant alterations in relapsing-remitting multiple sclerosis patients. Mult. Scler. Relat. Disord. 2018, 19, 79-84.

135. Carroll, L.D.; Davies, M.J. Reaction of Selenium Compounds with Oxygen Species and the Control of Oxidative Stress. In Organoselenium Compounds in Biology and Medicine: Synthesis, Biological and Therapeutic Treatments. Eds: Jain, V.K.; Priyadarsini, K.I., Eds; Royal Society of Chemistry; United Kingdom; 2018; pp. 254-275.

136. Xiao, W.; Loscalzo, J. Metabolic Responses to Reductive Stress. Antioxid. Redox Signal 2020, 32(18), 1330-1347.

137. Korge, P.; Calmettes, G.; Weiss, .JN. Increased reactive oxygen species production during reductive stress: The roles of mitochondrial glutathione and thioredoxin reductases. Biochim. Biophys. Acta 2015, 1847(6-7), 514-525.

138. Bradshaw, P.C. Cytoplasmic and Mitochondrial NADPH-Coupled Redox Systems in the Regulation of Aging. Nutrients 2019, 11(3), 504.

139.

Pérez-Torres, I.; Guarner-Lans, V.; Rubio-Ruiz, M.E. Reductive Stress in Inflammation-Associated Diseases and the Pro-Oxidant Effect of Antioxidant Agents. Int. J. Mol. Sci. 2017, 18, 2098.

140. Jozefczak, M.; Remans, T.; Vangronsveld, J.; Cuypers, A. Glutathione Is a Key Player in Metal-Induced Oxidative Stress Defenses. Int. J. Mol. Sci. 2012, 13, 3145-3175

141. Singhal, S.S.; Singh, S.P.; Singhal, P.; Horne, D.; Singhal, J.; Awasthi, S. Antioxidant Role of Glutathione S-Transferases: 4-Hydroxynonenal, a Key Molecule in Stress-Mediated Signaling. Toxicol. Appl. Pharmacol. 2015, 289(3), 361-370.

142. Bocedi, A.; Noce, A.; Marrone, G.; Noce, G.; Cattani, G.; Gambardella, G.; Di Lauro, M.; Di Daniele, N.; Ricci, G. Glutathione Transferase P1-1 an Enzyme Useful in Biomedicine and as Biomarker in Clinical Practice and in Environmental Pollution. Nutrients 2019, 11, 1741. 
143. Shukla, V.K.; Jensen, G.E.; Clausen, J. Erythrocyte glutathione perioxidase deficiency in multiple sclerosis. Acta Neurol. Scand., 1977, 56(6), 542-550.

144. Szeinberg, A.; Golan, R.; Ben Ezzer, J.; Sarova-Pinhas, I.; Sadeh, M.; Braham, J. Decreased erythrocyte glutathione peroxidase activity in multiple sclerosis. Acta Neurol. Scand. 1979, 60(5), 265-271.

145. Szeinberg, A.; Golan, R.; Ben-Ezzer, J.; Sarova-Pinhas, I.; Kindler, D. Glutathione peroxidase activity in various types of blood cells in multiple sclerosis. Acta Neurol. Scand. 1981, 63(1), 67-75.

146. Ljubisavljevic, S.; Stojanovic, I.; Cvetkovic, T.; Vojinovic, S.; Stojanov, D.; Stojanovic, D.; Bojanic, V.; Stokanovic, D.; Pavlovic, D. Glutathione homeostasis disruption of erythrocytes, but not glutathione peroxidase activity change, is closely accompanied with neurological and radiological scoring of acute CNS inflammation. Neuroimmunomodulation 2014, 21(1), 13-20.

147. Zachara, B.; Gromadzinska, J.; Czernicki, J.; Maciejek, Z.; Chmielewski, H. Red blood cell glutathione peroxidase activity in multiple sclerosis. Klin. Wochenschr., 1984, 62(4), 179-182.

148. Calabrese, V.; Raffaele, R.; Cosentino, E.; Rizza, V. Changes in cerebrospinal fluid levels of malondialdehyde and glutathione reductase activity in multiple sclerosis. Int. J. Clin. Pharmacol. Res. 1994, 14(4), 119-123.

149. Jensen, G.E.; Gissel-Nielsen, G.; Clausen, J. Leucocyte glutathione peroxidase activity and selenium level in multiple sclerosis. J. Neurol. Sci. 1980, 48(1), 61-67.

150. Reiter, R.J.; Tan, D.X.; Rosales-Corral, S.; Galano, A.; Zhou, X.J.; Xu, B. Mitochondria: Central Organelles for Melatonin's Antioxidant and Anti-Aging Actions. Molecules 2018, 23, 509.

151. Jensen, G.E. Clausen, J. Glutathione peroxidase and reductase, glucose-6-phosphate dehydrogenase and catalase activities in multiple sclerosis. J. Neurol. Sci. 1984, 63(1), 45-53.

152. Ljubisavljevic, S.; Stojanovic, I.; Vojinovic, S.; Stojanov, D.; Stojanovic, S.; Kocic, G.; Savic, D.; Cvetkovic, T.; Pavlovic, D. Cerebrospinal fluid and plasma oxidative stress biomarkers in different clinical phenotypes of neuroinflammatory acute attacks. Conceptual accession: from fundamental to clinic. Cell Mol. Neurobiol. 2013, 33(6), 767-777.

153. Belcastro, E.; Gaucher, C.; Corti, A.; Leroy, P.; Lartaud, I.; Pompella, A. Regulation of Protein Function by S-nitrosation and S-glutathionylation: Processes and Targets in Cardiovascular Pathophysiology. Biol. Chem. 2017, 398(12), 1267-1293.

154. Mahmoudian, E.; Khalilnezhad, A.; Gharagozli, K.; Amani, D. Thioredoxin-1, redox factor-1 and thioredoxin-interacting protein, mRNAs are differentially expressed in Multiple Sclerosis patients exposed and non-exposed to interferon and immunosuppressive treatments. Gene 2017, 634, 29-36.

155. Voigt, D.; Scheidt, U.; Derfuss, T.; Brück, W.; Junker, A. Expression of the Antioxidative Enzyme Peroxiredoxin 2 in Multiple Sclerosis Lesions in Relation to Inflammation. Int. J. Mol. Sci. 2017, 18, 760.

156. Todisco, S.; Convertini, P.; Iacobazzi, V.; Infantino, V. TCA Cycle Rewiring as Emerging Metabolic Signature of Hepatocellular Carcinoma. Cancers 2020, 12, 68.

157. Schaur, R.J.; Siems, W.; Bresgen, N.; Eckl, P.M. 4-Hydroxy-nonenal-A Bioactive Lipid Peroxidation Product. Biomolecules 2015, 5, 2247-2337.

158. McArdle, B.; Mackenzie, I.C.; Webster, G.R. STUDIES ON INTERMEDIATE CARBOHYDRATE METABOLISM IN MULTIPLE SCLEROSIS. J. Neurol. Neurosurg. Psychiatry, 1960, 23(2), 127-132.

159. Nijland, P.G.; Molenaar, R.J.; van der Pol, S.M.; van der Valk, P.; van Noorden, C.J.; de Vries, H.E.; van Horssen, J. Differential expression of glucose-metabolizing enzymes in multiple sclerosis lesions. Acta Neuropathol. Commun. 2015, 3, 79.

160. Hirsch, H.E.; Blanco, C.E. Parks, M.E. Glycerol phosphate dehydrogenase: reduced activity in multiple sclerosis plaques confirms localization in oligodendrocytes. J. Neurochem. 1980, 34(3), 760-762.

161. Cores, Á.; Piquero, M.; Villacampa, M.; León, R.; Menéndez, J.C. NRF2 Regulation Processes as a Source of Potential Drug Targets against Neurodegenerative Diseases. Biomolecules 2020, 10, 904.

162. Orrù, C.; Perra, A.; Kowalik, M.A.; Rizzolio, S.; Puliga, E.; Cabras, L.; Giordano, S.; Columbano, A. Distinct Mechanisms Are Responsible for Nrf2-Keap1 Pathway Activation at Different Stages of Rat Hepatocarcinogenesis. Cancers 2020, 12, 2305.

163. Lamichane, S.; Dahal Lamichane, B.; Kwon, S.-M. Pivotal Roles of Peroxisome Proliferator-Activated Receptors (PPARs) and Their Signal Cascade for Cellular and Whole-Body Energy Homeostasis. Int. J. Mol. Sci. 2018, 19, 949.

164. Xi, Y.; Zhang, Y.; Zhu, S.; Luo, Y.; Xu, P.; Huang, Z. PPAR-Mediated Toxicology and Applied Pharmacology. Cells 2020, 9, 352. 
1119

1120

1121

1122

1123

1124

1125

1126

1127

1128

1129

1130

1131

1132

1133

1134

1135

1136

1137

1138

1139

1140

1141

1142

1143

1144

1145

1146

1147

1148

1149

1150

1151

1152

1153

1154

1155

1156

1157

1158

1159

1160

1161

1162

1163

1164

1165

1166

1167

1168

1169

1170
165. Vargas-Mendoza, N.; Morales-González, Á.; Madrigal-Santillán, E.O.; Madrigal-Bujaidar, E.; Álvarez-González, I.; García-Melo, L.F.; Anguiano-Robledo, L.; Fregoso-Aguilar, T.; Morales-Gonzalez, J.A. Antioxidant and Adaptative Response Mediated by Nrf2 during Physical Exercise. Antioxidants (Basel) 2019, 8(6), 196.

166. Ferret-Sena, V.; Capela, C.; Sena, A. Metabolic Dysfunction and Peroxisome Proliferator-Activated Receptors (PPAR) in Multiple Sclerosis. Int. J. Mol. Sci. 2018, 19, 1639.

167. Witte, M.E.; Nijland, P.G.; Drexhage, J.A.; Gerritsen, W.; Geerts, D.; van Het Hof, B.; Reijerkerk, A.; de Vries, H.E.; van der Valk, P.; van Horssen, J. Reduced expression of PGC-1 $\alpha$ partly underlies mitochondrial changes and correlates with neuronal loss in multiple sclerosis cortex. Acta Neuropathol. 2013, 125(2), 231-243.

168. Del Bo', C.; Bernardi, S.; Marino, M.; Porrini, M.; Tucci, M.; Guglielmetti, S.; Cherubini, A.; Carrieri, B.; Kirkup, B.; Kroon, P.; Zamora-Ros, R.; Hidalgo Liberona, N.; Andres-Lacueva, C.; Riso, P. Systematic Review on Polyphenol Intake and Health Outcomes: Is there Sufficient Evidence to Define a Health-Promoting Polyphenol-Rich Dietary Pattern? Nutrients 2019, 11, 1355.

169. Shenkin, A. Micronutrients in health and disease. Postgrad. Med. J. 2006, 82(971), 559-567.

170. Koola, M.M. Galantamine-Memantine combination in the treatment of Alzheimer's disease and beyond. Psychiatry Res. 2020, 293, 113409.

171. Koola, M.M.; Jafarnejad, S.; Looney, S.; Praharaj, S.; Pillai, A.; Ahmed, A.; Slifstein, M. Meta-Analyses of Randomized Controlled Trials and Potential Novel Combination Treatments in Schizophrenia. Biol. Psychiatry 2020, 87(9), S306.

172. Zhang, Y.; Li, L.; Zhang, J. Curcumin in antidepressant treatments: An overview of potential mechanisms, pre-clinical/clinical trials and ongoing challenges. Basic Clin. Pharmacol. Toxicol. 2020, 10.1111/bcpt.13455.

173. Peris, E.; Micallef, Peter.; Paul, A.; Palsdottir, V.; Enejder, A.; Bauzá-Thorbrügge, M.; Olofsson, C.S.; Asterholm, W.I. Antioxidant treatment induces reductive stress associated with mitochondrial dysfunction in adipocyte. J. Biol. Chem. 2019, 294(7), 2340-2352.

174. Pérez-Pérez, A.; Sánchez-Jiménez, F.; Vilariño-García, T.; Sánchez-Margalet, V. Role of Leptin in Inflammation and Vice Versa. Int. J. Mol. Sci. 2020, 21, 5887.

175. Feige, J.; Moser, T.; Bieler, L.; Schwenker, K.; Hauer, L.; Sellner, J. Vitamin D Supplementation in Multiple Sclerosis: A Critical Analysis of Potentials and Threats. Nutrients, 2020, 12, 783.

176. Oliveira, S.R.; Kallaur, A.P.; Simão, A.N.; Morimoto, H.K.; Lopes, J.; Panis, C.; Petenucci, D.L.; da Silva, E.; Cecchini, R.; Kaimen-Maciel, D.R.; Reiche, E.M. Oxidative stress in multiple sclerosis patients in clinical remission: association with the expanded disability status scale. J. Neurol. Sci. 2012, 321(1-2), 49-53.

177. Miller, E.; Walczak, A.; Saluk, J.; Ponczek, M.B.; Majsterek, I. Oxidative modification of patient's plasma proteins and its role in pathogenesis of multiple sclerosis. Clin. Biochem. 2012, 45(1-2), 26-30.

178. Sadowska-Bartosz, I.; Adamczyk-Sowa, M.; Gajewska, A.; Bartosz, G. Oxidative modification of blood serum proteins in multiple sclerosis after interferon or mitoxantrone treatment. J. Neuroimmunol. 2014, 266(1-2), 7-74.

179. Morel, A.; Bijak, M.; Niwald, M.; Miller, E.; Saluk, J. Markers of oxidative/nitrative damage of plasma proteins correlated with EDSS and BDI scores in patients with secondary progressive multiple sclerosis. Redox Rep. 2017, 22(6), 547-555.

180. Adamczyk-Sowa, M.; Galiniak, S.; Żyracka, E.; Grzesik, M.; Naparło, K.; Sowa, P.; Bartosz, G.; Sadowska-Bartosz, I. Oxidative Modification of Blood Serum Proteins in Multiple Sclerosis after Interferon Beta and Melatonin Treatment. Oxid. Med. Cell Longev. 2017, 2017, 7905148.

181. Rommer, P.S.; Greilberger, J.; Salhofer-Polanyi, S.; Auff, E.; Leutmezer, F. Herwig, R. Elevated levels of carbonyl proteins in cerebrospinal fluid of patients with neurodegenerative diseases. Tohoku J. Exp. Med. 2014, 234(4), 313-317.

182. Irani, D.N. Cerebrospinal fluid protein carbonylation identifies oxidative damage in autoimmune demyelination. Ann. Clin. Transl. Neurol. 2016, 4(2), 145-150.

183. Teixeira, D.; Fernandes, R.; Prudêncio, C.; Vieira, M. 3-Nitrotyrosine quantification methods: Current concepts and future challenges. Biochimie 2016, 125, 1-11.

184. Zabaleta, M.; Marino, R.; Borges, J. Camargo, B.; Ordaz, P.; De Sanctis, J.B.; Bianco, N.E. Activity profile in multiple sclerosis: an integrative approach. A preliminary report. Mult. Scler. 2002, 8(4), 343-349. 
1171

1172

1173

1174

1175

1176

1177

1178

1179

1180

1181

1182

1183

1184

1185

1186

1187

1188

1189

1190

1191

1192

1193

1194

1195

1196

1197

1198

1199

1200

1201

1202

1203

1204

1205

1206

1207

1208

1209

1210

1211

1212

1213

1214

1215

1216

1217

1218

1219

1220

1221

1222

1223

185. Iarlori, C.; Gambi, D.; Lugaresi, A.; Patruno, A.; Felaco, M.; Salvatore, M.; Speranza, L.; Reale, M. Reduction of free radicals in multiple sclerosis: effect of glatiramer acetate (Copaxone). Mult. Scler. 2008, 14(6), 739-748.

186. Seven, A.; Aslan, M.; Incir, S.; Altintas, A. Evaluation of oxidative and nitrosative stress in relapsing remitting multiple sclerosis: effect of corticosteroid therapy. Folia Neuropathol. 2013, 51(1), 58-64.

187. Stojanovic, I.; Vojinovic, S.; Ljubisavljevic, S.; Pavlovic, R.; Basic, J.; Pavlovic, D.; Ilic, A.; Cvetkovic, T.; Stukalov, M. INF- $\beta 1 \mathrm{~b}$ therapy modulates L-arginine and nitric oxide metabolism in patients with relapse remittent multiple sclerosis. J. Neurol. Sci. 2012, 323(1-2), 187-192.

188. Poerschke, R.L.; Fritz, K.S.; Franklin, C.C. Methods to detect protein glutathionylation. Curr. Protoc. Toxicol. 2013, 57, 6.17.1-6.17.18.

189. Srivastava, D.; Kukkuta Sarma, G.R.; Dsouza, D.S.; Muralidharan, M.; Srinivasan, K.; Mandal, A.K. Characterization of residue-specific glutathionylation of CSF proteins in multiple sclerosis - A MS-based approach. Anal Biochem. 2019, 564-565, 108-115.

190. Garibaldi, S.; Barisione, C.; Marengo, B.; Ameri, P.; Brunelli, C.; Balbi, M.; Ghigliotti, G. Advanced Oxidation Protein Products-Modified Albumin Induces Differentiation of RAW264.7 Macrophages into Dendritic-Like Cells Which Is Modulated by Cell Surface Thiols. Toxins (Basel) 2017, 9(1), 27.

191. Hányšová, S.; Čierny, D.; Petráš, M.; Lehotský, J. Elevated plasma levels of advanced oxidation protein products in Slovak multiple sclerosis patients: possible association with different disability states. Act Nerv. Super Rediviva. 2017, 59(2), 45-50.

192. Gill, V.; Kumar, V.; Singh, K.; Kumar, A.; Kim, J.-J. Advanced Glycation End Products (AGEs) May Be a Striking Link Between Modern Diet and Health. Biomolecules 2019, 9, 888.

193. Wetzels, S.; Vanmierlo, T.; Scheijen, J.L.J.M.; van Horssen, J.; Amor, S.; Somers, V.; Schalkwijk, C.G.; Hendriks, J.J.A.; Wouters, K. Methylglyoxal-Derived Advanced Glycation Endproducts Accumulate in Multiple Sclerosis Lesions. Front. Immunol. 2019, 10, 855.

194. Tain, Y.; Hsu, C. Toxic Dimethylarginines: Asymmetric Dimethylarginine (ADMA) and Symmetric Dimethylarginine (SDMA). Toxins, 2017, 9, 92.

195. Haghikia, A.; Kayacelebi, A.A., Beckmann, B.; Hanff, E.; Gold, R.; Haghikia, A.; Tsikas, D. Serum and cerebrospinal fluid concentrations of homoarginine, arginine, asymmetric and symmetric dimethylarginine, nitrite and nitrate in patients with multiple sclerosis and neuromyelitis optica. Amino Acids 2015, 47(9), 1837-1845.

196. Zarkovic, N. Antioxidants and Second Messengers of Free Radicals. Antioxidants 2018, 7, 158.

197. Ito, F.; Sono, Y.; Ito, T. Measurement and Clinical Significance of Lipid Peroxidation as a Biomarker of Oxidative Stress: Oxidative Stress in Diabetes, Atherosclerosis, and Chronic Inflammation. Antioxidants (Basel), 2019, 8(3), 72.

198. Teunissen, C.E.; Sombekke, M.; van Winsen, L.; Killestein, J.; Barkhof, F.; Polman, C.H.; Dijkstra, C.D.; Blankenstein, M.A.; Pratico, D. Increased plasma 8,12-iso-iPF2alpha- VI levels in relapsing multiple sclerosis patients are not predictive of disease progression. Mult. Scler. 2012, 18(8), 1092-1098.

199. Miller, E.; Mrowicka, M.; Saluk-Juszczak, J.; Ireneusz, M. The level of isoprostanes as a non-invasive marker for in vivo lipid peroxidation in secondary progressive multiple sclerosis. Neurochem. Res. 2011, 36(6), 1012-1016.

200. Gonzalo, H.; Brieva, L.; Tatzber, F.; Jové, M.; Cacabelos, D.; Cassanyé, A.; Lanau-Angulo, L.; Boada, J.; Serrano, J.C.; González, C.; Hernández, L.; Peralta, S.; Pamplona, R.; Portero-Otin, M. Lipidome analysis in multiple sclerosis reveals protein lipoxidative damage as a potential pathogenic mechanism. J. Neurochem. 2012, 123(4), 622-634.

201. Greco, A.; Minghetti, L.; Sette, G.; Fieschi, C.; Levi, G. Cerebrospinal fluid isoprostane shows oxidative stress in patients with multiple sclerosis. Neurology 1999, 53(8), 1876-1879.

202. Pohl, E.E.; Jovanovic, O. The Role of Phosphatidylethanolamine Adducts in Modification of the Activity of Membrane Proteins under Oxidative Stress. Molecules 2019, 24, 4545.

203. Ghabaee, M.; Jabedari, B.; Al-E-Eshagh, N.; Ghaffarpour, M.; Asadi, F. Serum and cerebrospinal fluid antioxidant activity and lipid peroxidation in Guillain-Barre syndrome and multiple sclerosis patients. Int. J. Neurosci. 2010, 120(4), 301-304.

204. Pawlowski, J.; Shukla, P.; Bielekova, B. Identifying CSF Biomarkers of Oxidative Stress in Patients with Multiple Sclerosis. 2011. DOI: 10.13140/RG.2.1.4335.2082. Available online: 
1224

1225

1226

1227

1228

1229

1230

1231

1232

1233

1234

1235

1236

1237

1238

1239

1240

1241

1242

1243

1244

1245

1246

1247

1248

1249

1250

1251

1252

1253

1254

1255

1256

1257

1258

1259

1260

1261

1262

1263

1264

1265

1266

1267

1268

1269

1270

1271

1272

1273

1274

1275

1276
https://www.researchgate.net/publication/290998239_Identifying_CSF_Biomarkers_of_Oxidative_Stress_i n_Patients_with_Multiple_Sclerosis (28 August 2020)

205. Villoslada, P.; Alonso, C.; Agirrezabal, I.; Kotelnikova, E.; Zubizarreta, I.; Pulido-Valdeolivas, I.; Saiz, A.; Comabella M.; Montalban, X.; Villar, L.; Alvarez-Cermeño, J.C.; Fernández, O.; Alvarez-Lafuente, R.; Arroyo, R.; Castro, A. Metabolomic signatures associated with disease severity in multiple sclerosis. Neurol. Neuroimmunol. Neuroinflamm. 2017, 4(2), e321.

206. Håkansson, I.; Gouveia-Figueira, S.; Ernerudh, J.; Vrethem, M.; Ghafouri, N.; Ghafouri, B.; Nording, M. Oxylipins in cerebrospinal fluid in clinically isolated syndrome and relapsing remitting multiple sclerosis. Prostaglandins Other Lipid Mediat. 2018, 138, 41-47.

207. Fellows Maxwell, K.; Bhattacharya, S.; Bodziak, M.L.; Jakimovski, D.; Hagemeier, J.; Browne, R.W.; Weinstock-Guttman, B.; Zivadinov, R.; Ramanathan, M. Oxysterols and apolipoproteins in multiple sclerosis: a 5 year follow-up study. J. Lipid Res. 2019, 60(7), 1190-1198.

208. Palavra, F.; Marado, D.; Mascarenhas-Melo, F.; Sereno, J.; Teixeira-Lemos, E.; Nunes, C.C.; Gonçalves, G.; Teixeira, F; Reis, F. New markers of early cardiovascular risk in multiple sclerosis patients: oxidized-LDL correlates with clinical staging. Dis. Markers 2013, 34(5), 341-348.

209. Besler, H.T.; Comoğlu, S. Lipoprotein oxidation, plasma total antioxidant capacity and homocysteine level in patients with multiple sclerosis. Nutr. Neurosci. 2003, 6(3), 189-196.

210. Salemi, G.; Gueli, M.C.; Vitale, F.; Battaglieri, F.; Guglielmini, E.; Ragonese, P.; Trentacosti, A.; Massenti, M.F.; Savettieri, G.; Bono, A. Blood lipids, homocysteine, stress factors, and vitamins in clinically stable multiple sclerosis patients. Lipids Health Dis. 2010, 9, 19.

211. Meyers, L.; Groover, C.J.; Douglas, J.; Lee, S.; Brand, D.; Levin, M.C. Gardner, L.A. A role for Apolipoprotein A-I in the pathogenesis of multiple sclerosis. J. Neuroimmunol. 2014, 277(1-2), 176-185.

212. van de Kraats, C.; Killestein, J.; Popescu, V.; Rijkers, E.; Vrenken, H.; Lütjohann, D.; Barkhof, F.; Polman, C.H.; Teunissen, C.E. Oxysterols and cholesterol precursors correlate to magnetic resonance imaging measures of neurodegeneration in multiple sclerosis. Mult. Scler. 2014, 20(4), 412-417.

213. Graille, M.; Wild, P.; Sauvain, J.-J; Hemmendinger, M.; Guseva Canu, I.; Hopf, N.B. Urinary 8-OHdG as a Biomarker for Oxidative Stress: A Systematic Literature Review and Meta-Analysis. Int. J. Mol. Sci. 2020, 21, 3743.

214. Ibitoye, R.; Kemp, K.C.; Rice, C.; M. Hares, K.M., Scolding, N.J.; Wilkins, A. Oxidative stress-related biomarkers in multiple sclerosis: a review. Biomark. Med. 2016, 10(8), 889-902.

215. Taguchi, Y.-H.; Wang, H. Exploring MicroRNA Biomarkers for Parkinson's Disease from mRNA Expression Profiles. Cells 2018, 7, 245.

216. Brito, L.M.; Ribeiro-dos-Santos, Â.; Vidal, A.F.; de Araújo, G.S., on behalf of the Alzheimer's Disease Neuroimaging Initiative; Differential Expression and miRNA-Gene Interactions in Early and Late Mild Cognitive Impairment. Biology 2020, 9, 251.

217. Catanesi, M.; d'Angelo, M.; Tupone, M.G.; Benedetti, E.; Giordano, A.; Castelli, V.; Cimini, A. MicroRNAs Dysregulation and Mitochondrial Dysfunction in Neurodegenerative Diseases. Int. J. Mol. Sci. 2020, 21, 5986.

218. Mohammed, E.M.A. Environmental Influencers, MicroRNA, and Multiple Sclerosis. J. Cent. Nerv. Syst. Dis. 2020, 12, 1179573519894955.

219. Martinez, B.; Peplow, P.V. MicroRNAs in blood and cerebrospinal fluid as diagnostic biomarkers of multiple sclerosis and to monitor disease progression. Neural. Regen. Res. 2020, 15, 606-619.

220. Pfaff, A.L.; Bubb, V.J.; Quinn, J.P.; Koks, S. An increased burden of highly active 3 retrotransposition competent L1s is associated with 4 Parkinson's disease risk and progression in the PPMI 5 cohort. Int. J. Mol. Sci. 2020 (submitted).

221. Geis, F.K.; Goff, S.P. Silencing and Transcriptional Regulation of Endogenous Retroviruses: An Overview. Viruses 2020, 12, 884.

222. Török, N.; Molnár, K.; Füvesi, J.; Karácsony, M.; Zsiros, V.; Fejes-Szabó, A.; Fiatal, S.; Ádány, R.; Somogyvári, F.; Stojiljković, O.; Vécsei, L.; Bencsik, K. Chemokine receptor V $\Delta 32$ deletion in multiple sclerosis patients in Csongrád County in Hungary and the North-Bácska region in Serbia. Hum Immunol. 2015 Jan;76(1):59-64.

223. Hall, A.; Bandres-Ciga, S.; Diez-Fairen, M.; Billingsley, K.J. Genetic risk profiling in Parkinson's disease and utilizing genetics to gain insight into disease-related biological pathways. Submitted to Int. J. Mol. Sci. 
224. Dhama, K.; Latheef, S.K.; Dadar, M.; Samad, H.A.; Munjal, A.; Khandia, R.; Karthik, K.; Tiwari, R.; Yatoo,

1278 M.I.; Bhatt, P.; Chakraborty, S.; Singh, K.P.; Iqbal, H.M.N.; Chaicumpa, W.; Joshi, S.K. Biomarkers in Stress

1279 Related Diseases/Disorders: Diagnostic, Prognostic, and Therapeutic Values. Front. Mol. Biosci. 2019, 6, 91. 